\title{
DESENVOLVIMENTO DE ECTOCYCLOPS RUBESCENS (BRADY 1904) (COPEPODA, CRUSTACEA)
}

\author{
M. APPARECIDA JULIANO DE CARVALHO*
}

Departamento de Zoologia - Instituto de Biociências - U.S.P. - São Paulo.

1. INTRODUÇÃO $\ldots \ldots \ldots \ldots \ldots \ldots \ldots \ldots \ldots \ldots \ldots$

2. METODOLOGIA ................... 245

3. ESTUDO MORFOLÓGICO DOS NÁUPLIOS $\ldots . . . .347$

4. ESTUDO MORFOLÓGICO DOS COPEPÓDITOS ... 356

5. ESTUDO DA TAXA DE CRESCIMENTO DOS COPEPÓDITOS ..................... 359

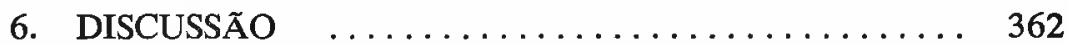

7. CONCLUSÕES $\ldots \ldots \ldots \ldots \ldots \ldots \ldots \ldots \ldots \ldots \ldots \ldots \ldots \ldots$

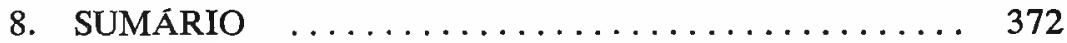

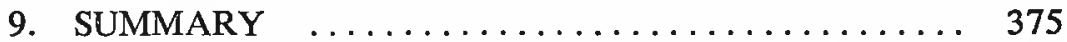

10. BIBLIOGRAFIA $\ldots \ldots \ldots \ldots \ldots \ldots \ldots \ldots \ldots \ldots . \ldots \ldots$

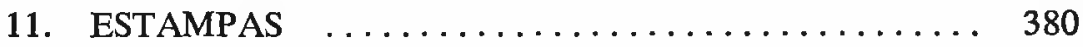

RESUMO - O estudo morfológico das fases de desenvolvimento de náuplio I e copepódito V - da espécie Ectocyclops rubescens (Brady, 1904), em Cyclopoida das águas límnicas, foi realizado à partir de exúvias obtidas de criações efetuadas em laboratório. As características de cada fase foram descritas e as fases naupliares, comparadas com as de Ectocyclops pharelatus (Koch, 1838). Foi estabelecida a taxa de crescimento para copepóditos de E. rubescens.

ABSTRACT - Ectocyclops rubescens (Brady, 1904) has 5 naupliar stages and 5 copepodite stages before adulthood. It is

- Bolsista da Fundação de Amparo à Pesquisa do Estado de São Paulo. 
found mostly among water plants in fresh-water reservoirs in the State of São Paulo, Brazil. It is easily reared under laboratory conditions and descriptions were made of the exuviae thus obtained. These were compared with the developmental stages of Ectocyclops pharelatus (Koch, 1838), and the conclusion was reached that $E$. rubescens and $E$. pharelatus are different species.

The growth rate of the copepodites of $E$. rubescens was established.

\section{INTRODUÇÃO}

Este trabalho tem como objetivo o estudo das fases de desenvolvimento de Ectocyclops rubescens, um Cyclopoida muito comum nas águas límnicas do Estado de São Paulo e também coletado na zona do Rio Tocantins, no Estado do Pará.

Embora possua o Brasil um dos maiores potenciais hidrográficos do mundo, o estudo dos Cyclopoida límnicos tem sido realizado em áreas territoriais bastante restritas. Entre os pesquisadores que trabalharam com espécies brasileiras podemos citar: Kiefer (1933, 1935, 1936a 1936b, 1936c) autor de espécies do norte e nordeste; Oliveira (1954) que redescreveu Mesocyclops longisetus encontrado na lagoa litorânea de Maricá, Estado do Rio de Janeiro e Lindberg (1954), que no seu trabalho de levantamento de Cyclopoida da América do Sul, descreveu a sub-espécie Oithona amazonica continentales da região de Manaus.

Nenhum destes autores tentou estudar o ciclo de desenvolvimento das espécies encontradas, nem procurou estabelecer a extensão geográfica da distribuição de cada uma.

Conhecer o ciclo de espécies comuns em corpos d'água é de valor para a determinação das cadeias alimentares nessas águas e constitui base para o estudo da produção em cada local, pois, em animais como copépodos com numerosos estágios de desenvolvimento, cada um ocupará um nicho diferente na ecologia do corpo d'água, devido ao tamanho điferente, se não por outras causas. 
Ectocyclops rubescens foi descrito por Brady (1904) e possue uma situação sistemática muito controvertida. Kiefer (in Rilov 1963) o considera como espécie, enquanto Dussart (1969) é de opinião que se trata de uma sub-espécie de Ectocyclops pharelatus.

Vários autores, entre os quais Dietrich (1961), Byrnes (1921), Ziegelmayer (1925), Ewers (1930), Dukina (1956), Auvray \& Dussart $(1966,1967)$ e Dussart (1969) se preocuparam com o estudo das fases de desenvolvimento de copépodos Calanoida, Cyclopoida e Harpacticoida de água doce. $\mathrm{O}$ número de náuplios em $\mathrm{Cy}-$ clopoida é um ponto de controvérsia entre eles. Uns admitem seis fases naupliares, enquanto outros, apenas cinco.

Vários autores admitem que os crustáceos crescem segundo a lei de Brooks. Teissier (1960) nega que tal lei possa ser generalizada para todos os crustáceos, mas admite que muitos deles a seguem. Hanaoka (1952) em um estudo realizado com náuplios de Calanoida, Cyclopoida e Harpacticoida constatou que, quando bentônicos, costeiros (marinhos) ou de água doce, esses animais crescem segundo a lei de Brooks.

Concluindo, são vários os problemas a resolver neste trabalho:

1) descobrir as fases de desenvolvimento da espécie e descrevê-las;

2) verificar se E. rubescens é uma espécie diversa de E. pharelatus ou se é apenas uma sub-espécie e para tanto comparar também as fases de desenvolvimento de ambas (descritas para $E$. pharelatus por Ewers em 1930);

$3)$ tentar estabelecer com certeza o número de fases naupliares para a espécie (se 5 ou 6 );

4) determinar se os copepóditos obedecem a uma lei de crescimento e se esta lei é a de Brooks.

Em estudos posteriores tentarei estabelecer os limites da distribuição desta espécie, assim como continuar o levantamento faunístico e biológico dos Cyclopoida do Brasil.

2.

\section{METODOLOGIA}

Os animais para estudo foram coletados em lagoas e represas do Estado de São Paulo, principalmente na Raia Olímpica da Cida- 
de Universitária Armando Salles de Oliveira e na represa de Americana. As coletas foram realizadas em épocas diferentes do ano.

Coletei plantas aquáticas que foram levadas para o laboratório juntamente com água do local. As plantas foram lavadas em uma bacia de plástico e a seguir passadas para outra bacia com água; ambas foram conservadas e nas duas, com auxílio de pipeta, tive oportunidade de coletar material.

As fêmeas ovadas foram separadas e mantidas em placas de Petri de $4,5 \mathrm{~cm}$ de diâmetro e $1,5 \mathrm{~cm}$ de altura com água e fragmentos de plantas do local de origem. Duas a três vezes por semana eram colocadas nos aquários, de uma a quatro pipetadas de água das bacias acima mencionadas. Isto serviu de alimento aos animais.

Os micro-aquários foram colocados sobre uma mesa próxima à janela, sofrendo toda a variação de luz possível, recebendo inclusive sol durante a tarde. Os animais se desenvolveram bem durante todo $o$ ano.

Como a espécie não apresenta o fenômeno de canibalismo, a fêmea era mantida no aquário após o nascimento dos náuplios. Obtive então várias "ninhadas" de náuplios de uma mesma fêmea.

Todos os dias os micro-aquários eram examinados à lupa e as exúvias coletadas e passadas para uma solução de formol a $4 \%$. Us adultos que se desenvolveram nos aquários se entre-cruzaram e novas gerações foram obtidas. Quando a concentração de animais de um recipiente era muito alta, novos aquários eram montados para as fêmeas ovadas. Mantive a criação por cerca de dois anos.

Para identificação do gênero e espécie, vários animais foram dissecados. As patas, antenas e peças bucais foram desenhadas ao microscópio com auxílio de câmara clara. Os desenhos das peças assim obtidos, bem como desenhos do aspecto geral do animal foram confrontados então com os desenhos e descrições da literatura existente.

O estudo dos náuplios e copepóditos foi realizado com base nas exúvias obtidas, mantidas em solução de formol à $4 \%$ e coradas com tinta de escrever Parker-Quink (azul lavável).

Para estudo da taxa de crescimento foram medidas 50 exúvias de cada fase. Foram feitos esboços dos animais, em vista dorsal, ao micrnscópio com auxílio de câmara clara. As medidas foram tomadas da extremidade da cabeça à da furca, com exceção das cerdas 
furcais. Devido ao grande número de cálculos a serem realizados foi utilizado computador eletrônico.

3.

\title{
ESTUDO MORFOLÓGICO DOS NĀUPLIOS
}

\begin{abstract}
NĀUPLIO I
(Figs. 1, 6, 7, 8)

Comprimento do corpo: Devido à extrema delicadeza das exúvias das primeiras fases é muito difícil a obtenção de peças completas e perfeitamente distendidas para medidas fidedignas. Assim, apesar de termos analisado grande número delas, só pudemos medir sete exúvias da fase I, com os seguintes comprimentos em milímetros: 0,$097 ; 0,099 ; 0,109 ; 0,111$; 0,$120 ; 0,128$.

Forma do corpo: $\quad$ arredondada, ligeiramente oval (Fig. 1).

Apêndices:

em número de três pares - antênulas, anbordos anterior e posterior e uma fileira de cílios na extremidade posterior.

Labrum: tem uma fileira de cílios de cada lado nos tenas e mandíbulas.
\end{abstract}

ANTENULA (Fig. 6) com quatro artículos, sendo o primeiro de difícil visualização e sem qualquer ornamentação; o segundo com uma cerda e uma fileira de espínulos; o terceiro com duas cerdas e uma fileira de espínulos; o quarto com duas cerdas no ápice e duas fileiras de espínulos.

ANTENA (Fig. 7) formada de coxópodo largo, com uma forte lâmina mastigadora e uma fileira de espínulos no limite com o basípodo. Basípodo largo, com duas cerdas e uma fileira de espínulos. Endópodo, formado de apenas um artículo, que termina por um forte espinho e uma fileira de espínulos pré-distal de onde partem cerdas. 
Exópodo, formado por quatro artículos, apresentando o primeiro, que é o mais largo, uma cerda curta e duas fileiras de espínulos; os dois seguintes, uma longa cerda e fileiras de espínulos; o quarto, que é o mais longo e afilado, três cerdas, sendo a terminal muito longa.

MANDIBULA (Fig. 8) formada de coxópodo reduzido com uma cerda. Basípodo grande (largo e longo), com duas cerdas. Endópodo, bi-articulado, apresentando um dos artículos duas lâminas mastigadoras espinhosas de grossura diferente e uma fileira dorsal de espínulos na porção média do artículo; o outro, com três cerdas simples de tamanhos diferentes. Exópodo, formado por quatro artículos, cada um com uma longa cerda (cerca de 9 vezes o tamanho do artículo) e o artículo distal, apresentando ainda um espinho.

Armadura caudal:

A extremidade posterior do corpo é arredondada e apresenta um par de cerdas furcais (Fig. 1). A relação "cerdas caudais-tamanho do corpo" é de aproximadamente $1: 3,7$.

\section{NĀUPLIO II}

(Figs. 2, 9, 10, 11, 12)

Comprimento do corpo: Seis exúvias com os seguintes comprimentos em milímetros: 0,$122 ; 0,130 ; 0,130$; 0,$136 ; 0,141 ; 0,146$.

Forma do corpo:

nitidamente oval (Fig. 2).

Labrum:

apresenta uma fileira de cílios nos bordos anteriores direito e esquerdo e uma na extremidade posterior. Internamente apresenta ainda uma fileira de cílios pré-marginais posteriores e dois tufos, marginando o lado anterior de duas áreas internas.

Apêndices:

em número de quatro pares - antênulas, antenas, mandíbulas e maxílulas.

ANTENULA (Fig. 9) com quatro artículos, sendo o primeiro de difícil visualização, sem qualquer ornamentação; o segundo 
com uma cerda; o terceiro com duas cerdas e uma fileira de espínulos; o quarto com três cerdas no ápice e duas fileiras de espínulos.

ANTENA (Fig. 10) com coxópodo largo, com uma lâmina mastigadora espinhosa e uma cerda tão grande quanto a lâmina; este artículo contém ainda uma fileira de espínulos no limite com o basípodo. Basípodo, largo com três cerdas e uma fileira de espínulos. Endópodo, formado de apenas um artículo, que termina por um forte espinho e uma fileira de espínulos pré-distal, de onde partem cerdas. Exópodo, formado por quatro artículos, apresentando o primeiro, que é o mais largo, uma cerda curta; os dois seguintes, uma cerda cada um; o quarto, que é o mais longo e mais fino, três cerdas sendo muito longa a que ocupa a extremidade distal do artículo.

MANDIBULA (Fig. 11) formada de coxópodo reduzido, apresentando apenas uma cerda. Basípodo grande (largo e longo) com duas cerdas marginais internas e uma fileira de 3 espínulos na região média da outra margem. Endópodo bi-articulado, apresentando um dos artículos uma lâmina mastigadora espinhosa, duas cerdas e ainda uma fileira dorsal de espínulos na sua porção média; o outro apresenta quatro cerdas simples de tamanhos diferentes. Exópodo, formado por quatro artículos, possuindo cada um uma longa cerda (cerca de 6 vezes o tamanho do artículo), o artículo distal apresenta ainda um espinho.

MAXILULA (Fig. 12) representada nesta fase por duas cerdas apenas, uma do lado direito e outra do esquerdo.

Campo delimitado por

cílios:

têm origem nesta fase dois campos delimitados por cílios dispostos em ferradura. Tais campos estão situados ventralmente, um de cada lado, um pouco abaixo das margens laterais direita e esquerda do labrum, em posição inclinada em relação ao maior eixo do corpo do animal.

Armadura caudal:

a extremidada posterior do corpo é mais estreita que a anterior, apresentando ainda apenas um par de cerdas (Fig. 2). A rela- 
ção "cerda caudal-tamanho do corpo" ế de aproximadamente $1: 5,4$.

\section{NÁUPLIO III}

(Figs. 3, 13, 14, 15, 16)

Comprimento do corpo: pudemos medir 14 exúvias que variaram de 0,129 a $0,156 \mathrm{~mm}$ e apresentaram a seguinte distribuição.

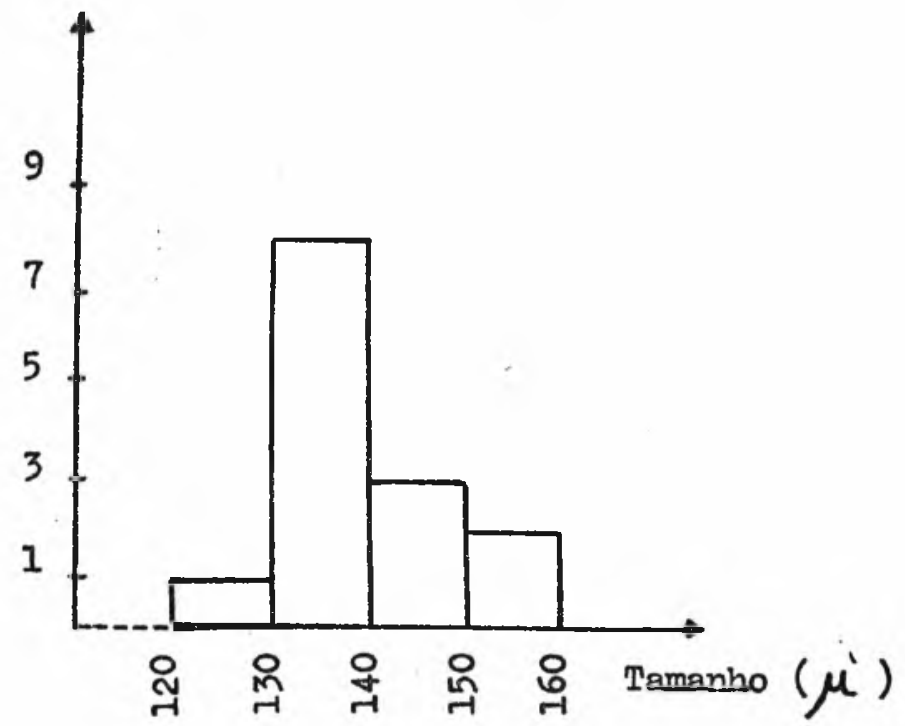

Forma do corpo: oval (Fig. 3)

Labrum:

com cílios marginais posteriores e anteriores externos e do lado interno da margem posterior duas fileiras de cílios sendo a menor mais interna, talvez delimitando a boca.

Apêndice:

em número de quatro pares: antênulas, antenas, mandíbulas e maxílulas.

ANTENULA (Fig. 13) formada de quatro artículos, sendo o primeiro de difícil visualização, sem qualquer ornamentação; o segundo com uma cerda e uma fileira de espínulos no limite com o 
terceiro; o terceiro com duas cerdas, uma fileira de espínulos mediana e uma no limite com o quarto; o quarto com quatro cerdas no ápice e uma fileira de espínulos.

ANTENA (Fig. 14) com coxópodo largo, com uma lâmina mastigadora espinhosa e uma cerda, ambas de tamanho semelhante; uma fileira de espínulos ocupa a região mediana anterior do coxópodo. Basípodo largo com três cerdas, uma fileira de espínulos e um espinho na região mediana anterior, uma segunda fileira de espínulos está no limite basípodo-exópodo. Endópodo, formado de apenas um artículo, que termina por um forte espinho, e uma fileira de espínulos disposta em espiral de onde partem as cerdas. Exópodo, formado por quatro artículos apresentando o primeiro, que é o mais largo, uma cerda pequena; os dois seguintes, uma cerda cada, e o quarto, que é mais fino e longo que os demais, três cerdas sendo muito longa a do ápice.

ANTENA (Fig. 14) com coxópodo largo, com uma lâmina sentando apenas uma cerda. Basípodo grande (largo e longo) com duas cerdas. Endópodo bi-articulado, apresentando um dos artículos uma lâmina mastigadora espinulada, duas cerdas e uma fileira de espínulos que ocupa a porção média dorsal; o outro, com quatro cerdas simples de tamanhos diferentes. Exópodo, formado por quatro artículos possuindo cada um uma cerda, sendo o artículo distal armado também de um espinho.

MAXILULAS (Fig. 16) representadas nesta fase, por duas cerdas apenas, uma no lado direito e outra no lado esquerdo ventral.

Campo delimitado por dois campos ciliares com situação ventral, cílios (Fig. 3): um pouco posteriores, um à margem lateral esquerda e outro à margem lateral direita do labrum. Estes campos têm a forma de uma ferradura e posição inclinada em relação ao maior eixo do corpo.

Segmentação:

aparece nesta fase a primeira segmentação do corpo do animal.

Armadura caudal: a extremidade posterior do corpo é afunilada e apresenta dois pares de cerdas fur- 
cais. A relação "cerda furcal maior-tamanho do corpo" é de aproximadamente 1:4, 6. (Fig. 3)

\section{NÅUPLIO IV}

(Figs. 4, 17, 18, 19, 20)

Comprimento do corpo: medimos 29 exúvias que variaram entre 0,158 a $0,206 \mathrm{~mm}$ e apresentaram a seguinte distribuição.

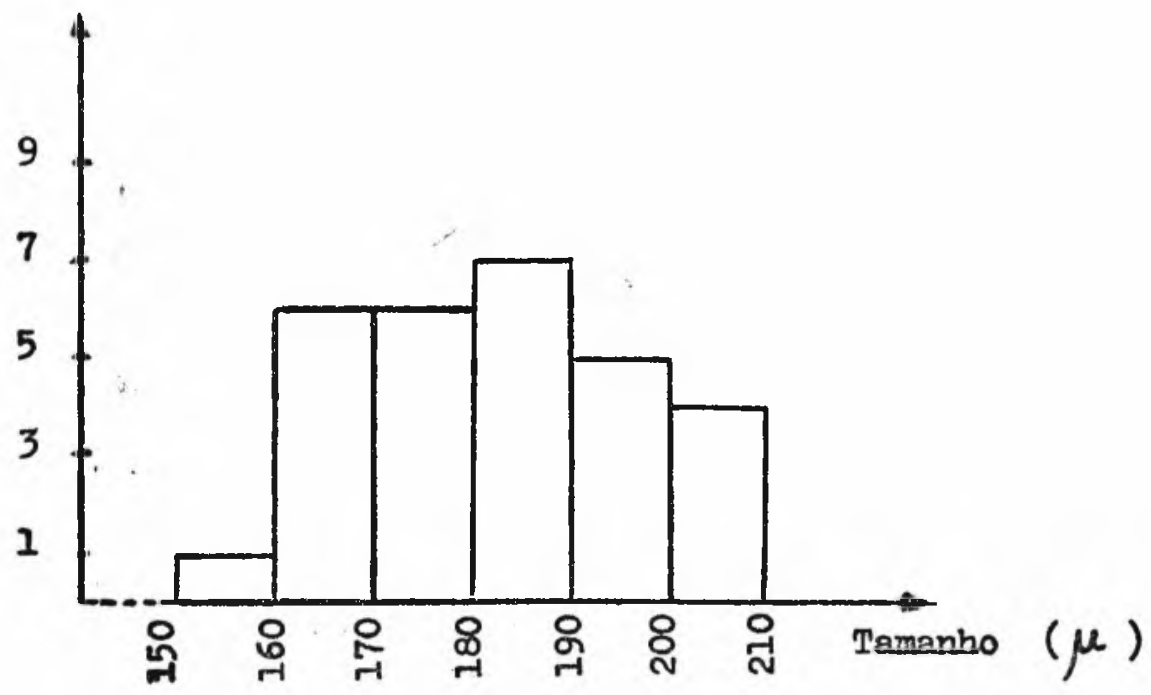

Forma do corpo: oval (Fig. 4)

Labrum: com uma fileira de cílios nos bordos anteriores direito e esquerdo e uma na extremidade posterior. Internamente ocorre uma fileira de cílios pré-marginais posteriores e dois tufos marginando o lado anterior de duas áreas internas. Internamente ainda aparecem dois tufos de cílios delimitando áreas mais ou menos circulares. 
Apêndice:

em número de quatro pares: antênulas, antenas, mandíbulas e maxílulas.

ANTENULA (Fig. 17) com quatro artículos. O primeiro não possue ornamentos e é de difícil visualização; o segundo possue uma cerda e um espinho; o terceiro, duas cerdas e uma fileira de espínulos na região mediana; o quarto artículo possue quatro cerdas apicais, uma simples sub-apical, uma fileira de espínulos medianos e dois espinhos na margem interna.

ANTENA (Fig. 18) com coxópodo largo possuidor de uma lâmina mastigadora espinhosa e uma cerda; com duas fileiras de espínulos, uma mediana e a outra no limite com o artículo seguinte. Basípodo largo com três cerdas; uma fileira de espínulos mais ou menos mediana e uma no limite com o exópodo. Endópodo formado por um artículo que termina por forte espinho, uma fileira de espinulos pré-distal serve de ponto de inserção para as cerdas. Exópodo com quatro artículos: o primeiro, que é o mais largo, com um espinho e uma cerda pequena; os dois seguintes, com uma longa cerda cada um; o quarto, que é o mais fino e 3 vezes mais longo que o precedente, com três cerdas, duas sub-apicais e uma apical muito grande. Os três últimos artículos têm ainda cérdulas minúsculas ou espínulos na proximidade da base de inserção das cerdas.

MANDIBULA (Fig. 19) com coxópodo pequeno com uma cerda. Basípodo largo, com três cerdas. Endópodo bi-articulado, tendo o primeiro artículo uma lâmina mastigadora espinhosa, duas cerdas e uma fileira de espínulos que ocupa a região mediana dorsal; o segundo, com quatro cerdas simples. Exópodo formado por quatro artículos, apresentando cada um uma cerda e o artículo distal, além da cerda, um espinho.

MAXILULA (Fig. 20) constituida nesta fase por dois lobos. O lobo interno com três cerdas de tamanhos diferentes; a mais interna, pequena e espinhosa; a média, plumosa, tendo cerca de duas vezes o tamanho da primeira e a terceira, muito longa (cerca de 7,5 vezes o tamanho da primeira). O lobo externo também com três cerdas quase iguais; a mais interna tem o tamanho médio e $\epsilon$ espinhosa, a mediana é a menor e também possue espinhos; a mais externa $́$ a maior e plumosa. 
Campo delimitado por cílios delimitam duas regióes em forma de cílios (Fig. 4): ferradura de situação ventral, um pouco posteriormente à margem lateral direita e à esquerda do labrum. Esses campos ciliares têm uma posição inclinada em relação ao maior eixo do corpo do animal.

Armadura caudal:

a extremidade posterior do corpo é afunilada e apresenta dois pares de cerdas e um par de espinhos. A relação "cerda furcal maior-tamanho do corpo" é de aproximadamente $1: 5,8$ (Fig. 4)

\section{NÁUPLIO V}

(Figs. 5, 21, 22, 23, 24)

Comprimento do corpo: 30 exúvias de 0,164 a $0,250 \mathrm{~mm}$ com a seguinte distribuição:

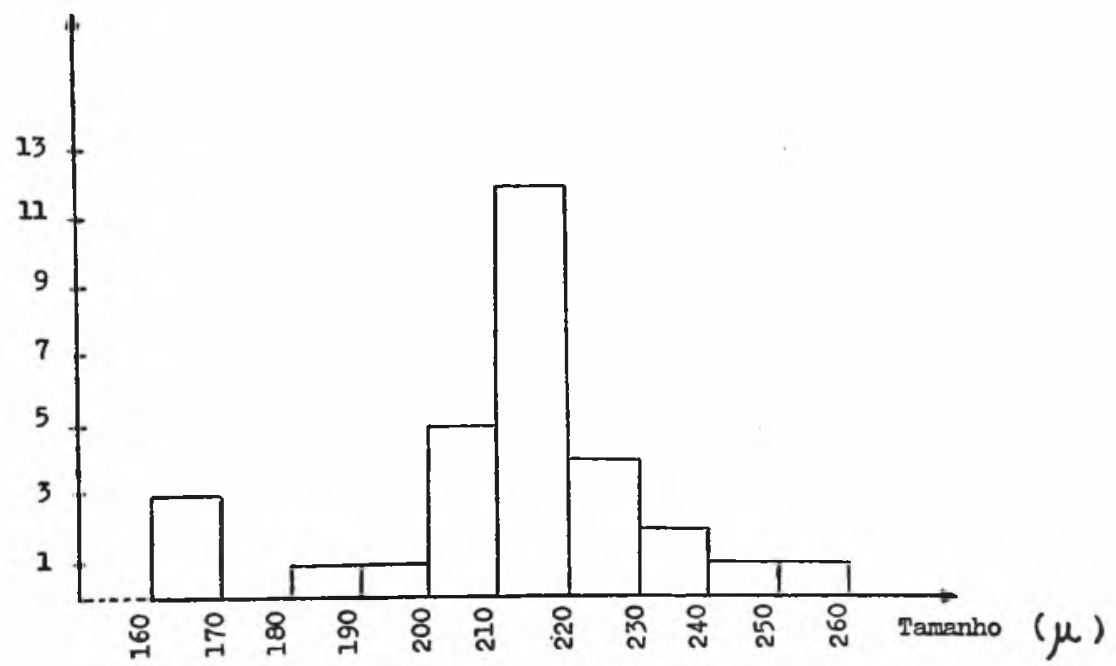


Forma do corpo:

Labrum:

Apêndice: oval (Fig. 5)

com uma fileira de cílios nos bordos anteriores direito e esquerdo e uma na margem posterior. Internamente existe 2 fileiras de cílios pré-marginais posteriores e dois tufos marginando o lado anterior de duas áreas internas; internamente ainda, aparecem dois tufos de cílios delimitando áreas mais ou menos circulares perto da margem posterior.

em número de quatro pares: antênulas, antenas, mandíbulas e maxílulas.

ANTENULA (Fig. 21) com quatro artículos; o primeiro, pouco visível e com uma fileira de espínulos no limite com o segundo; o segundo artículo, com uma cerda e uma fileira de espínulos no limite com o terceiro; o terceiro artículo, com duas cerdas e uma fileira de espínulos; quarto, com uma cerda mediana e cinco apicais, e uma fileira de espínulos.

ANTENA (Fig. 22) com coxópodo largo, com uma lâmina mastigadora espinhosa, uma cerda, e em sua região média, uma fileira de espínulos próxima da margem. Basípodo largo, com três cerdas marginais e uma fileira de espínulos medianos. Endópodo, formado de apenas um artículo com uma fileira de espínulos na face ventral dentre os quais partem as cerdas. $O$ endópodo termina por um forte espinho. Exópodo, formado por quatro artículos, apresentando o primeiro, que é o mais largo, uma cerda curta, os dois seguintes uma longa cerda cada um e o último, que é o mais fino e longo, três cerdas sendo duas sub-apicais curtas e uma apical muito longa. Os dois primeiros artículos têm uma fileira de espínulos junto à margem externa.

MANDIBULA (Fig. 23) com coxópodo pequeno e apenas uma cerda. Basípodo grande (largo e longo), com três cerdas e uma fileira de espínulos. Endópodo bi-articulado apresentando o primeiro artículo uma lâmina mastigadora espinhosa e duas cerdas, uma fileira de espínulos que ocupa a porção média dorsal do artículo; o se- 
gundo com cinco cerdas simples de tamanhos semelhantes. O exópodo é formado por quatro artículos, possuindo os três primeiros uma cerda cada e o último duas cerdas (uma pequena e uma grande) e um espinho.

MAXILULA (Fig. 24) agora com um basípodo diferenciado, articulado com dois lobos. O lobo interno apresenta quatro cerdas de tamanhos e estruturas desiguais; as três mais internas são relativamente do mesmo tamanho, sendo duas nuas e uma com espinhos; a quarta é muito longa, tem cerca de 8.5 vezes o tamanho da menor. O lobo externo tem três cerdas mais ou menos do mesmo tamanho e um grupo de espínulos na zona de implantação da cerda mais externa.

Campo delimitado por cílios delimitam duas áreas em forma de cílios (Fig. 5): ferradura, ventrais, cada uma um pouco posterior à margem lateral esquerda e direita do labrum. Os campos ciliares têm uma posição inclinada em relação ao maior eixo do corpo do animal.

Armadura caudal: a extremidade posterior do corpo é afunilada e apresenta três pares de cerdas furcais. A relação "cerda furcal maior-tamanho do corpo" é de aproximadamente 1:5, 3 (Fig. 5)

4.

ESTUDO MORFOLOGICO DOS COPEPODITOS

COPEPÓDITO I

(Figs. 25, 30, 35, 38, 39, 40)

Corpo:

três segmentos torácicos, um abdominal e furca (Fig. 25). Foram medidas 50 exúvias cujo comprimento variou de 0,260 a 0,360 $\mathrm{mm}$, com moda em $0,320 \mathrm{~mm}$. 
Antênula:

Furca:

Patas:

Corpo:

Antênula:

Furca:

Patas: com quatro artículos apenas. $O 1^{\circ}$ mais longo que os outros 3 juntos e armada conforme Fig. 30.

possue uma cerda grande e três pequenas, mais 2 fileiras de espínulos, e margem interna plumosa (Fig. 35).

Patas I e II possuem apenas um artículo no exópodo e no endópodo, com cerdas e espínhos como desenhado na Fig. 38 e 39.

Pata III é representada apenas por um espinho. (Fig. 40).

\section{COPEDODITO $\amalg$}

(Figs. 26, 31, 36, 41, 42, 43, 44)

quatro segmentos torácicos, um abdominal e furca (Fig. 26). Foram medidas 50 exúvias cujo comprimento variou de 0,340 a $0,460 \mathrm{~mm}$, com moda em $0,350 \mathrm{~mm}$.

apresenta ainda quatro artículos, com cerdas distribuidas como na Fig. 31.

uma cerda bem desenvolvida e quatro pequenas, mais 2 fileiras de espínulos conforme desenhado na Fig. 36.

Patas I e II têm dois artículos no exópodo e endópodo armados de cerdas e espinhos como na Fig. 41 e 42.

Pata III com um artículo no exópodo e endópodo, armados de cerdas e espinhos como na Fig. 43.

Pata IV constituida por dois espinhos apenas (Fig. 44). 


\section{COPEPÓDITO III}

(Figs. 27, 32, 37, 45, 46, 47, 48, 49)

Corpo:

Antênula:

Furca:

Patas:

Corpo:

Antênula:

Furca:

Patas: cinco segmentos torácicos, um abdominal e furca (Fig. 27). O comprimento de 50 exúvias variou entre 0,350 e $0,500 \mathrm{~mm}$, com moda em $0,390 \mathrm{~mm}$.

apresenta cinco artículos e cerdas distribuidas como na Fig. 32.

bem desenvolvida, já com o aspecto da furca do adulto, diferindo apenas quanto ao tamanho, com cerdas e espínulos como na Fig. 37.

Patas I e II e III com dois artículos no exópodo e no endópodo, armados com cerdas e espinhos como nas Figs. 45, 46 e 47. Pata IV possue apenas um artículo no exópodo e endópodo armados com cerdas e espinhos como na Fig. 48.

Pata V é um espinho cerdoso (Fig. 49).

\section{COPEPÓDITO IV}

(Figs. 28, 33, 50, 51, 52, 53, 54, 55)

com cinco segmentos torácicos, dois abdominais e furca (Fig. 28). O comprimento de 50 exúvias variou entre 0,440 a 0,600 $\mathrm{mm}$ com moda em $0,460 \mathrm{~mm}$.

ainda com cinco artículos e cerdas como na Fig. 33.

semelhante a do adulto.

Patas I, II, III e IV com dois artículos no exópodo e endópodo guarnecido de cerdas e espinhos como nas Figs. 50, 51, 52 e 53. 
São semelhantes aos do copepódito III.

Pata V é uma protuberância com 1 espinho cerdoso, 2 cerdas plumosas e duas fileiras de espínulos (Fig. 54).

Pata VI são dois espinhos e só ocorre no macho (Fig. 55).

O aparecimento da pata VI já indica um dimorfismo sexual neste estágio.

COPEPÓDITO $\mathrm{V}$

(Figs. 29 e 34)

Corpo:

com cinco segmentos torácicos, três abdominais e furca (Fig. 29). O comprimento de 50 exúvias variou entre 0,540 e 0,680 $\mathrm{mm}$, com moda em $0,560 \mathrm{~mm}$. Ausência de abertura genital.

Antênula:

com sete artículos e cerdas distribuidas como na Fig. 34.

Furca:

semelhante a do adulto.

Patas: iguais às do adulto. As patas I, II, III e IV com três artículos no exópodo e no endópodo guarnecidos de cerdas e espinhos.

Pata V protuberância com um espinho cerdoso, duas cerdas plumosas e 2 fileiras de espínulos.

Pata VI, presente no macho com três espinhos cerdosos.

5.

\section{ESTUDO DA TAXA DE CRESCIMENTO DOS COPEPODITOS}

Primeiro procurei verificar se havia dependência entre tamanho e fase dos animais que estudei. Para tanto coloquei em um gráfico o tamanho médio de cada fase contra o número da mesma e 
obtive a seguinte curva Graf. 1, que demonstra que realmente existe uma dependência entre tamanho e fase.

Analiticamente uma relação entre tamanho e fase é também sugerida pela análise da matriz de coeficientes de correlação expressa na Matriz de coeficientes de correlação.

Matriz de coeficientes de correlação

$\begin{array}{lcccc}\text { Variável } & \text { Tamanho } & \begin{array}{c}\text { Classe } \\ (=\text { fase })\end{array} & \begin{array}{c}\text { log } \\ \text { tamanho }\end{array} & \begin{array}{c}\text { Classe }^{2} \\ \left(=\text { fase }^{2}\right)\end{array} \\ \text { tamanho } & 1 & 0,93507 & 0,99436 & 0,93699 \\ \text { classe ( = fase }) & & 1 & 0,94097 & 0,98110 \\ \log \text { tamanho } & & & 1 & 0,92803 \\ \text { classe }^{2}\left(=\text { fase }^{2}\right) & & & & 1\end{array}$

Observada a matriz notamos uma alta correlação positiva 0,93507 - entre tamanho e classe ( $=$ fase). Note-se que a correlação entre log tamanho e classe é maior ainda - 0,99436.

\section{ESPECIFICAÇĀO DA FUNÇĀO:}

Fiz uso da técnica estatística de análise de regressão, através do método dos mínimos quadrados.

Usei o método indutivo e para tanto efetuei quatro estimativas de modelos de crescimento a fim de estabelecer a forma especificativa que melhor descrevesse o comportamento do fenômeno em consideração.

Os modelos estimados foram:

1 - Linear - com a forma especificativa $\mathrm{Y}=\mathrm{a}+\mathrm{bX}$

2 - Quadrática $I$ - com a forma especificativa $Y=a+b X^{2}$

3 - Quadrática II - com forma especificativa $\mathrm{Y}=\mathrm{a}+\mathrm{bX}+$ $\mathrm{cX}^{2}$

4 - Exponencial - com forma especificativa $Y=a e^{b X}$

As variáveis utilizadas foram:

$\mathrm{Y}_{1}$ - variável dependente - $\mathrm{i}$ variando de 1 a 250 - sig- 


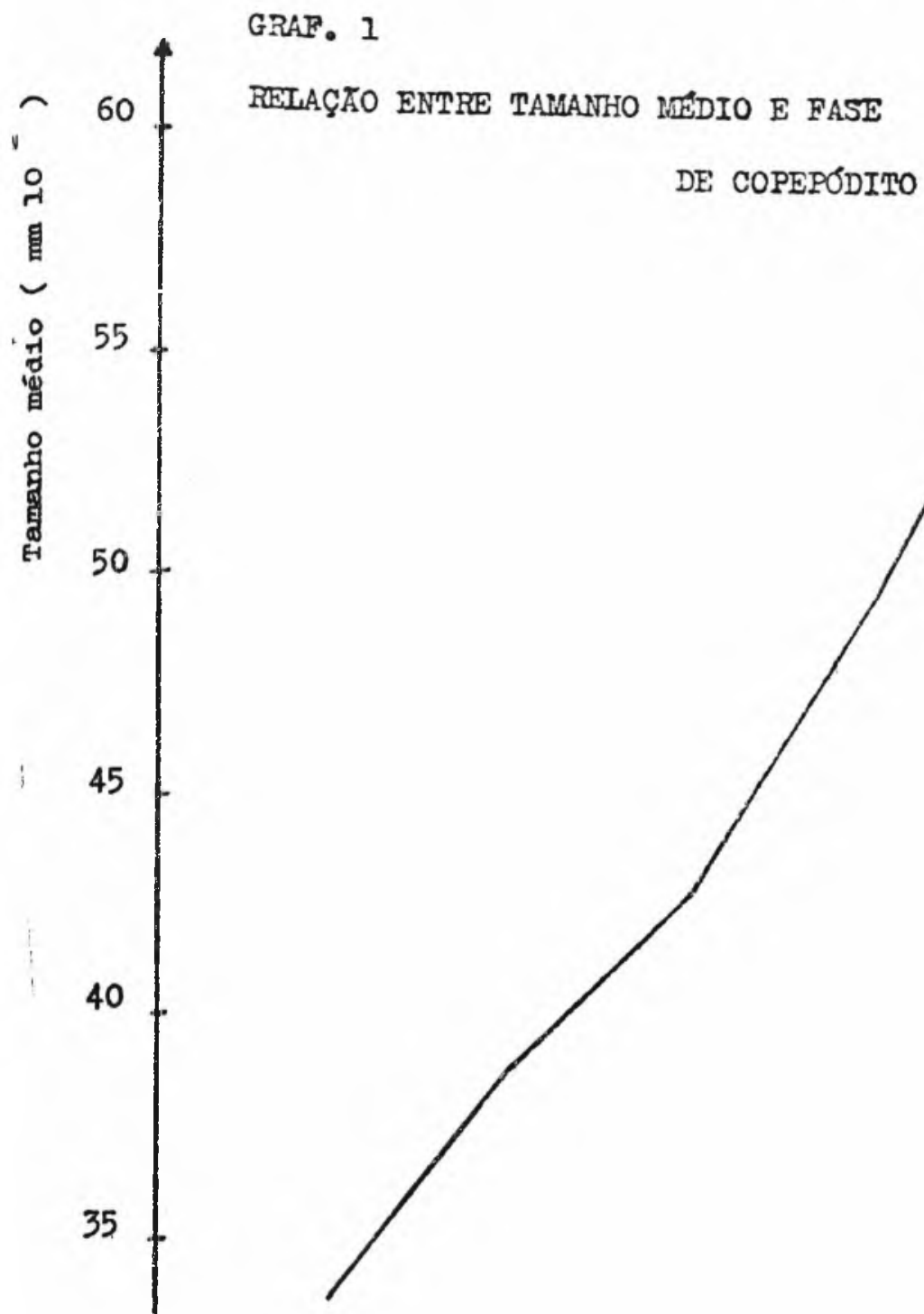


nificando o tamanho dos copepóditos, cabeça à furca, com exceção das cerdas furcais.

$\mathrm{X}_{1}$ - variável independente $-\mathrm{i}$ variando de 1 a 5 - significando as fases que chamaremos de classes.

O número de observaçōes foi de 250; correspondendo 50 observações a cada uma das classes.

A forma que mais se ajustou ao fenômeno foi a exponencial, por isso me utilizei dela para obter a taxa de crescimento da espécie.

Assim, ajustando a expressão $4 \quad \mathrm{Y}=\alpha \mathrm{e}^{\mathrm{bX}}$

Resultou: $\quad Y=0,02921 . \mathrm{e}^{0,1315 \mathrm{X}}$

Chamei de taxa de crescimento à diferença entre duas fases consecutivas dividida pela primeira fase considerada.

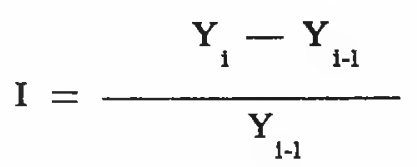

Onde:

$$
\begin{aligned}
\mathbf{I} & =\text { taxa de crescimento } \\
\mathbf{Y}_{1} & =\text { fase considerada } \\
\mathbf{Y}_{\mathbf{1}-\mathbf{I}} & =\text { fase imediatamente anterior à fase considerada }
\end{aligned}
$$

Lembrando então nossa forma exponencial:

$$
Y=\alpha e^{b x}
$$

Temos:

$$
\begin{aligned}
Y_{1} & =\alpha \mathrm{e}^{b_{1}} \\
Y_{1-1} & =\alpha \mathrm{e}^{b(1-1)}
\end{aligned}
$$

Substituindo os valores na equação (1) obtive uma taxa de crescimento de $14 \%$ para a espécie Ectocyclops rubescens, que cresce segundo a lei de Brooks.

6.

\section{DISCUSSÃO}

O gênero Ectocyclops foi descrito por Brady (1904) e segundo Dussart (1969) apresenta uma sistemática ainda pouco clara. As vá- 
rias formas descritas recentemente são consideradas tanto como sub-espécies quanto como espécie, dependendo de cada autor. A maior parte das espécies deste gênero é inter-tropical.

A espécie Ectocyclops rubescens é pela primeira vez assinalada no Brasil. Na América do Sul ela já foi mencionada em 1934 por Lowndes, no Paraguai (Lindberg 1954).

Dussart (1969) considera Ectocyclops rubescens como sub-espécie de $E$. pharelatus. Para o citado autor, $E$. pharelatus é cosmopolita aparecendo, no entanto, em maior densidade no hemisfério norte. A sub-espécie $E$. pharelatus rubescens ocorre no hemisfério sul. Kiefer (in Rilov, 1963), considera E. rubescens como espécie distinta.

Ectocyclops rubescens difere de E. pharelatus no aduito pelos caracteres assinalados no quadro $\mathbf{I}$.

QUADRO I - Comparação da distribuição de artículos, cerdas e espinhos no adulto das espécies $E$. rubescens, Brady 1904 e E. pharelatus, Koch, 1838.

E. rubescens

$6 .^{\circ}$ artículo da antênula, curto. Cerda mais interna da $5 .^{\mathrm{a}}$ pata com dois tipos de espinhos: pequenos e grossos na ponta, longos e finos junto à base.

Cerda mais externa da $5 .^{\mathrm{a}}$ pata com espinhos delicados.

Antênula do macho com 11 artículos dos quais o $5 .^{\circ}$ e o $8 .^{\circ}$ estão parcialmente divididos em: 2 artículos, o 5.०; e 3 artículos, o $8 .^{\circ}$.

Todas as peças bucais complexas.
E. pharelatus

$6 .^{\circ}$ artículo da antênula longo. Cerda mais interna da $5 .^{\mathrm{a}}$ pata com todos os espinhos iguais. Cerda mais externa da $5 .^{\mathrm{a}}$ pata sem espinhos.

Antênula do macho com 17 artículos.

Peças bucais mais simplificadas. 
Diversos autores como Walter (1822), Ziegelmayer (1925), Ewers (1930) e Dukina (1956) descrevem para Cyclopoida de água doce seis fases naupliares, enquanto outros como Dietrich (1915), Rilov (1963) e Dussart (1969) aceitam apenas cinco fases. Dussart (1969) acredita que o tempo de duração da fase IV é maior, sofrendo o animal um crescimento sem que ocorra muda. Criando E. rubescens em laboratório, observei cinco fases naupliares, compreendendo: um ortonáuplio e quatro metanáuplios. O ortonáuplio tem a forma arredondada e os metanáuplios são ovais.

As fases naupliares de Ectocyclops rubescenes são comparadas, nos quadros que se seguem, com as fases naupliares de Ectocyclops pharelatus dos trabalhos de Ewers (1930) (descrição e desenhos) e de Dukina (in Dussart 1969) (apenas desenhos). Notam-se as seguintes diferenças.

QUADRO II - Quadro comparativo da distribuição de cerdas e artículos no náuplio I das espécies $E$. rubescens e $E$. pharelatus, este segundo descriçōes de Ewers (1930) e de Dukina (in Dussart 1969).

\begin{tabular}{|c|c|c|c|}
\hline \multirow{2}{*}{$\begin{array}{l}\text { Ramos e } \\
\text { artículos dos } \\
\text { apêndices }\end{array}$} & \multicolumn{3}{|c|}{ E S P E I E S } \\
\hline & E. rubescens & $\begin{array}{l}\text { E. pharelatus } \\
\text { (Ewers) }\end{array}$ & $\begin{array}{c}\text { E. pharelatus } \\
\text { (Dukina) }\end{array}$ \\
\hline $\begin{array}{l}\text { Antênula } \\
\text { artículo distal. } \\
\text { primeiro } \\
\text { artículo }\end{array}$ & $\begin{array}{l}\text { ornamentação } \\
\text { de espínulos } \\
\text { sem cerdas }\end{array}$ & $\begin{array}{l}\text { sem espínulos } \\
\text { sem cerdas }\end{array}$ & $\left\{\begin{array}{l}\text { sem espínulos } \\
\text { com uma cerda } \\
\text { longa }\end{array}\right.$ \\
\hline $\begin{array}{l}\text { Antena } \\
\text { endópodo } \\
\text { exópodo }\end{array}$ & $\begin{array}{l}\text { espinho terminal } \\
\text { menor que as } \\
\text { cerdas que são } 3 \\
\text { com } 4 \text { artículos: } \\
\text { cerda do } 1 .^{\circ} \\
\text { artículo pequena } \\
\text { cerda do } 3 .^{\circ} \\
\text { artículo grande. }\end{array}$ & $\begin{array}{l}\text { espinho terminal } \\
\text { maior que a } \\
\text { única cerda } \\
\text { existente com } \\
4 \text { artículos: } \\
\text { cerda do } 1 .^{\circ} \\
\text { artículo } \\
\text { grande, cerda } \\
\text { do } 3 .^{\circ} \text { artículo, } \\
\text { pequena }\end{array}$ & $\begin{array}{l}\text { só ocorrem } \\
\text { cerdas em } \\
\text { número de } 4 \\
\text { com } 5 \text { artículos } \\
\text { (Impossível a } \\
\text { comparação } \\
\text { das cerdas por } \\
\text { defeito de } \\
\text { impressão) }\end{array}$ \\
\hline
\end{tabular}




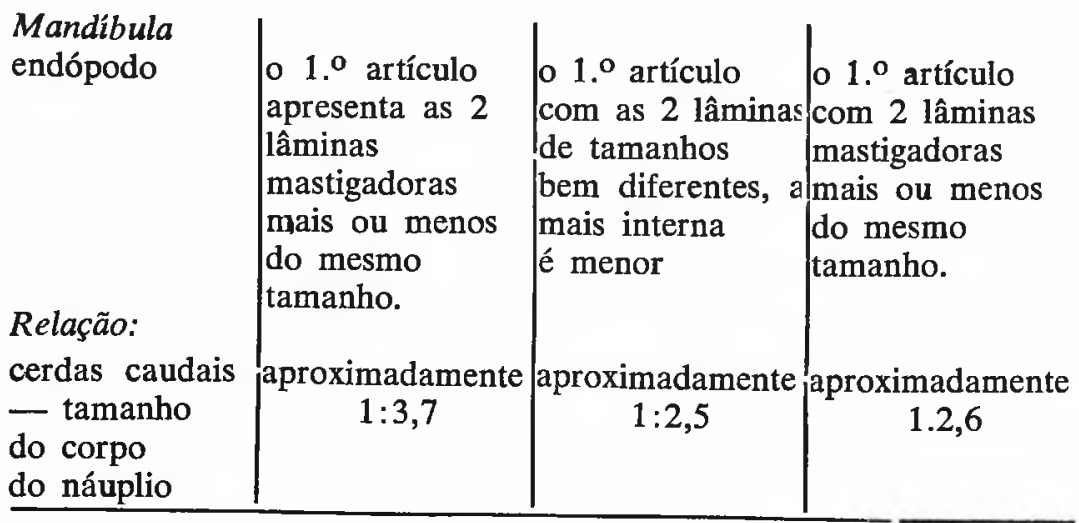

QUADRO III -- Quadro comparativo da distribuição de cerdas e artículos no náuplio II das espécies $E$. rubescens e E. pharelatus, este segundo descrições de Ewers (1930) e de Dukina (in Dussart 1969)

\begin{tabular}{|c|c|c|c|}
\hline \multirow{2}{*}{$\begin{array}{l}\text { Ramos e } \\
\text { artículos dos } \\
\text { apêndices }\end{array}$} & \multicolumn{3}{|c|}{ E S P E I E S } \\
\hline & E. rubescens & $\begin{array}{c}E \text {. pharelatus } \\
\text { (Ewers) }\end{array}$ & $\begin{array}{c}\text { E. pharelatus } \\
\text { (Dukina) }\end{array}$ \\
\hline $\begin{array}{l}\text { Antênula } \\
\text { 3. }{ }^{\circ} \text { artículo }\end{array}$ & com 2 cerdas & com 2 cerdas & com 3 cerdas \\
\hline $\begin{array}{l}\text { Antena } \\
\text { coxópodo }\end{array}$ & $\begin{array}{l}\text { com } 1 \text { lâmina } \\
\text { mastigadora }\end{array}$ & $\begin{array}{l}\text { com } 2 \text { lâminas } \\
\text { mastigadoras }\end{array}$ & $\begin{array}{l}\text { com } 1 \text { lâmina } \\
\text { mastigadora }\end{array}$ \\
\hline basípodo & com 3 cerdas & $\begin{array}{l}\text { com } 3 \text { cerdas } \\
\text { pequenas e uma } \\
\text { grande situada } \\
\text { no limite com } \\
\text { o exópodo }\end{array}$ & $\begin{array}{l}\text { com apenas } 3 \\
\text { cerdas pequenas }\end{array}$ \\
\hline $\begin{array}{l}\text { exópodo } \\
1 .^{\circ} \text { artículo }\end{array}$ & $\begin{array}{l}\text { com } 4 \text { artículos } \\
\text { com } 1 \text { cerda } \\
\text { curta no limite } \\
\text { com o } \\
2 .^{\circ} \text { artículo }\end{array}$ & $\begin{array}{l}\text { com } 3 \text { artículos } \\
\text { com } 1 \text { cerda longa } \\
\text { no limite } \\
\text { basípodo, } \\
\text { primeiro artículo }\end{array}$ & $\begin{array}{l}\text { com } 4 \text { artículos } \\
\text { com } 1 \text { grande } \\
\text { espinho na } \\
\text { região mediana } \\
\text { e } 1 \text { cerda curta } \\
\text { no limite com } \\
\text { o } 2 .^{\circ} \text { artículo }\end{array}$ \\
\hline $2 .^{\circ}$ artículo & $\begin{array}{l}\text { com 1 cerda } \\
\text { longa no limite } \\
\text { com o 3.० } \\
\text { artículo }\end{array}$ & $\begin{array}{l}\text { com } 1 \text { cerda } \\
\text { longa no limite } \\
\text { com o } 1 .^{\circ} \\
\text { artículo }\end{array}$ & $\begin{array}{l}\text { com } 1 \text { cerda } \\
\text { curta mediana e } \\
1 \text { longa no limite } \\
\text { com o } 3 .^{\circ} \\
\text { artículo }\end{array}$ \\
\hline
\end{tabular}




\begin{tabular}{|c|c|c|c|}
\hline $3 .^{\circ}$ artículo & $\begin{array}{l}\text { com } 1 \text { cerda } \\
\text { longa no limite } \\
\text { com o } 4 .^{\circ} \\
\text { artículo }\end{array}$ & $\begin{array}{l}\text { com } 1 \text { cerda } \\
\text { curta no limite } \\
\text { com o } 2 .^{\circ} \\
\text { artículo; } \\
1 \text { cerda longa } \\
\text { terminal e } \\
1 \text { curta } \\
\text { subterminal }\end{array}$ & $\mid \begin{array}{l}\text { com } 1 \text { cerda } \\
\text { média no } \\
\text { limite com o } 4 .^{\circ}\end{array}$ \\
\hline $4 .^{\circ}$ artículo & $\begin{array}{l}\text { com } 1 \text { cerda } \\
\text { longa } \\
\text { na ponta e } \\
2 \text { curtas } \\
\text { subterminais }\end{array}$ & ausente & $\begin{array}{l}\text { com 1 cerda } \\
\text { média terminal e } \\
1 \text { pequena } \\
\text { subterminal }\end{array}$ \\
\hline $\begin{array}{l}\text { Mandíbula } \\
\text { basípodo }\end{array}$ & $\begin{array}{l}\text { com } 2 \text { cerdas } \\
\text { pequenas }\end{array}$ & $\begin{array}{l}\text { com } 3 \text { cerdas } \\
\text { pequenas }\end{array}$ & $\begin{array}{l}\text { com } 2 \text { cerdas } \\
\text { pequenas }\end{array}$ \\
\hline $\begin{array}{l}\text { Campo } \\
\text { ciliado }\end{array}$ & $\begin{array}{l}\text { inclinado em } \\
\text { relação ao } \\
\text { maior eixo do } \\
\text { corpo }\end{array}$ & $\begin{array}{l}\text { perpendicular } \\
\text { ao maior } \\
\text { eixo do corpo }\end{array}$ & $\begin{array}{l}\text { perpendicular } \\
\text { ao maior eixo } \\
\text { do corpo }\end{array}$ \\
\hline Segmentação & ausente & presente & ausente \\
\hline $\begin{array}{l}\text { Relação: } \\
\text { cerdas caudais } \\
\text { - tamanho } \\
\text { do corpo }\end{array}$ & $\begin{array}{c}\text { aproximadamente } \\
1: 5,4\end{array}$ & $\begin{array}{c}\text { aproximadamente } \\
1: 4\end{array}$ & $\begin{array}{c}\text { aproximadamente } \\
1: 5\end{array}$ \\
\hline
\end{tabular}

QUADRO IV - Quadro comparativo da distribuição de cerdas e artículos no náuplio III das espécies $E$. rubescens e E. pharelatus, este segundo descrições de Ewers (1930) e Dukina (in Dussart 1969)

\begin{tabular}{l|l|l|l}
\hline $\begin{array}{l}\text { Ramos e } \\
\text { artículos dos } \\
\text { apêndices }\end{array}$ & E. pharelatus & $\begin{array}{l}\text { E S P E C I E S } \\
\text { E. pharelatus } \\
\text { (Ewers) }\end{array}$ & $\begin{array}{l}\text { E. pharelatus } \\
\text { (Dukina) }\end{array}$ \\
\hline $\begin{array}{l}\text { Antênula } \\
\text { artículo distal }\end{array}$ & $\begin{array}{l}\text { com 1 nova } \\
\text { cerda do mesmo } \\
\text { tamanho que } \\
\text { as outras }\end{array}$ & $\begin{array}{l}\text { com 1 nova } \\
\text { cerda } \\
\text { mais curta que } \\
\text { as outras }\end{array}$ & $\begin{array}{l}\text { com 1 nova } \\
\text { cerda do mesmo } \\
\text { que as outras }\end{array}$ \\
$\begin{array}{ll}\text { Antena } \\
\text { basípodo }\end{array}$ & $\begin{array}{l}\text { com 1 espinho } \\
\text { grande na região } \\
\text { média dorsal }\end{array}$ & espinho ausente & espinho ausente
\end{tabular}




\begin{tabular}{|c|c|c|c|}
\hline $\begin{array}{l}\text { exópodo } \\
\text { artículo distal }\end{array}$ & $\begin{array}{l}\text { com } 2 \text { cerdas } \\
\text { médias } \\
\text { sub-terminais }\end{array}$ & $\begin{array}{l}\text { sem cerdas } \\
\text { sub-terminais }\end{array}$ & $\begin{array}{l}\text { com } 2 \text { cerdas } \\
\text { sub-terminais }\end{array}$ \\
\hline $\begin{array}{l}\text { Mandíbula } \\
\text { basípodo }\end{array}$ & com 2 cerdas & com 3 cerdas & com 2 cerdas \\
\hline Segmentação & presente & presente & ausente \\
\hline $\begin{array}{l}\text { Relação: } \\
\text { cerdas caudais } \\
\text { - tamanho } \\
\text { do corpo }\end{array}$ & $\begin{array}{c}\text { aproximadamente } \\
1: 4,6\end{array}$ & $\begin{array}{c}\text { aproximadamente } \\
1: 4,8\end{array}$ & $\begin{array}{c}\text { aproximadamente } \\
1: 6,3\end{array}$ \\
\hline
\end{tabular}

QUADRO V - Quadro comparativo da distribuição de cerdas e artículos no náuplio IV das espécies $E$. rubescens e $E$. pharelatus, este segundo descrições de Ewers (1930) e Dukina (in Dussart 1969)

\begin{tabular}{|c|c|c|c|}
\hline \multirow{2}{*}{$\begin{array}{l}\text { Ramos e } \\
\text { artículos dos } \\
\text { apêndices }\end{array}$} & \multicolumn{3}{|c|}{ ESPECIES } \\
\hline & E. rubescens & $\begin{array}{c}\text { E. pharelatus } \\
\text { (Ewers) }\end{array}$ & $\begin{array}{c}\text { E. pharelatus } \\
\text { (Dukina) }\end{array}$ \\
\hline $\begin{array}{l}\text { Antena } \\
\text { exópodo }\end{array}$ & com 4 artículos & com 5 artículos & com 5 artículos \\
\hline $\begin{array}{l}\text { Mandíbula } \\
\text { basípodo }\end{array}$ & com 3 cerdas & com 4 cerdas & com 3 cerdas \\
\hline $\begin{array}{l}\text { endópodo } \\
1 .^{\circ} \text { artículo }\end{array}$ & $\begin{array}{l}\text { com } 1 \text { lâmina } \\
\text { forte e } 2 \text { cerdas } \\
\text { delicadas }\end{array}$ & $\begin{array}{l}\text { com } 3 \text { lâminas } \\
\text { fortes }\end{array}$ & $\begin{array}{l}\text { com } 1 \text { lâmina } \\
\text { forte } 1 \text { média } \\
\text { e } 1 \text { cerda } \\
\text { delicada }\end{array}$ \\
\hline $2 .^{\circ}$ artículo & $\begin{array}{l}\text { com } 4 \text { cerdas } \\
\text { praticamente } \\
\text { iguais }\end{array}$ & $\begin{array}{l}\text { com } 4 \text { cerdas } \\
\text { praticamente } \\
\text { iguais }\end{array}$ & $\begin{array}{l}\text { com } 5 \text { cerdas } \\
\text { desiguais: } 1^{0} \text { ) } \\
\text { mais interna, } \\
\text { muito pequena; } \\
2 .^{\circ} \text { ) cerca de } \\
1,5 \text { vezes a } 1 .^{\mathrm{a}} \text {, } \\
3 .^{\circ} \text { cerca de } \\
2 \text { vezes a } 1 .^{\mathrm{a}} ; \\
4 .^{\circ} \text { ) cerca de } \\
4 \text { vezes a } 1 .^{\mathrm{a}} \text { e a } \\
5 .^{\mathrm{a}} \text { igual à } 1 .^{\mathrm{a}}\end{array}$ \\
\hline
\end{tabular}




\begin{tabular}{l|l|l|l}
$\begin{array}{l}\text { Maxílula } \\
\text { exópodo }\end{array}$ & $\begin{array}{l}\text { com 3 cerdas de } \\
\text { tamanhos } \\
\text { nitidamente } \\
\text { diferentes }\end{array}$ & $\begin{array}{l}\text { com cerdas de } \\
\text { tamanhos } \\
\text { praticamente } \\
\text { iguais }\end{array}$ & $\begin{array}{l}\text { com 2 cerdas de } \\
\text { tamanhos } \\
\text { praticamente } \\
\text { iguais }\end{array}$ \\
\hline $\begin{array}{l}\text { Armadura } \\
\text { caudal }\end{array}$ & $\begin{array}{l}\text { com 2 pares de } \\
\text { cerdas e um par } \\
\text { de espinhos } \\
\text { pequenos }\end{array}$ & $\begin{array}{l}\text { com 2 pares de } \\
\text { cerdas e um par } \\
\text { de espinhos } \\
\text { pequenos }\end{array}$ & $\begin{array}{l}\text { com 3 pares de } \\
\text { cerdas }\end{array}$ \\
$\begin{array}{l}\text { Relação: } \\
\text { cerda maior } \\
\text { da armadura } \\
\text { caudal - } \\
\text { tamanho } \\
\text { do corpo }\end{array}$ & $\begin{array}{l}\text { aproximadamente } \\
1: 5,8\end{array}$ & $\begin{array}{l}\text { aproximadamente } \\
1: 4,5\end{array}$ & $\begin{array}{c}\text { aproximadamente } \\
1: 5\end{array}$ \\
\hline
\end{tabular}

QUADRO VI - Quadro comparativo da distribuição de cerdas e artículos no náuplio $\mathrm{V}$ das espécies $E$. rubescens e $E$. pharelatus, este segundo descrições de Ewers (1930) e Dukina (in Dussart 1969)

\begin{tabular}{|c|c|c|c|}
\hline & & ESPE I E & \\
\hline & E. rubescens & $\begin{array}{c}\text { E. pharelatus } \\
\text { (Ewers) }\end{array}$ & $\begin{array}{l}\text { E. pharelatus } \\
\text { (Dukina) }\end{array}$ \\
\hline $\begin{array}{l}\text { Antênula } \\
1 .^{\mathrm{a}} \text { cerda }\end{array}$ & $\begin{array}{l}\text { no limite } 2 .^{\circ}-3 .^{\circ} \\
\text { artículo }\end{array}$ & $\begin{array}{l}\text { na zona média } \\
\text { do } 3 .^{\circ} \text { artículo }\end{array}$ & $\begin{array}{l}\text { no zona média } \\
\text { do } 2 .^{\circ} \text { artículo }\end{array}$ \\
\hline $\begin{array}{l}\text { último } \\
\text { artículo }\end{array}$ & $\begin{array}{l}\text { com } 1 \text { cerda na } \\
\text { região mediana; } \\
3 \text { sub-apicais e } \\
2 \text { apicais }\end{array}$ & $\begin{array}{l}\text { com } 3 \text { cerdas } \\
\text { sub-apicais e } \\
2 \text { apicais }\end{array}$ & $\begin{array}{l}\text { todas as } 4 \text { cerdas } \\
\text { apicais }\end{array}$ \\
\hline $\begin{array}{l}\text { Antena } \\
\text { coxópodo }\end{array}$ & $\begin{array}{l}\text { com } 1 \text { lâmina } \\
\text { mastigadora e } \\
1 \text { cerda plumosa }\end{array}$ & $\begin{array}{l}\text { com } 2 \text { lâminas } \\
\text { mastigadora }\end{array}$ & $\begin{array}{l}\text { com } 1 \text { lâmina } \\
\text { mastigadora e } \\
1 \text { cerda } \\
\text { plumosa }\end{array}$ \\
\hline
\end{tabular}




\begin{tabular}{|c|c|c|c|}
\hline exópodo & $\left\{\begin{array}{l}4 \text { artículos } \\
\text { com } 3 \text { cerdas } \\
\text { muito longas, } \\
2 \text { médias e } \\
1 \text { pequena }\end{array}\right.$ & $\begin{array}{l}4 \text { artículos com } \\
3 \text { cerda muito } \\
\text { longas, } \\
2 \text { médias e } \\
4 \text { pequenas }\end{array}$ & $\mid \begin{array}{l}4 \text { artículos com } \\
3 \text { cerdas muito } \\
\text { longas, } 2 \text { médias } \\
\text { e } 1 \text { pequena }\end{array}$ \\
\hline $\begin{array}{l}\text { Mandibula } \\
\text { basípodo }\end{array}$ & $\begin{array}{l}\text { com } 3 \text { cerdas: } \\
1 \text { grande e } \\
2 \text { pequenas }\end{array}$ & $\begin{array}{l}\text { com } 5 \text { cerdas: } \\
2 \text { grandes e } \\
3 \text { pequenas }\end{array}$ & $\begin{array}{l}\text { com } 3 \text { cerdas: } \\
1 \text { grande, } \\
11 \text { média } \\
\text { e } 1 \text { pequena }\end{array}$ \\
\hline $\begin{array}{l}\text { endópodo } \\
1 .^{\circ} \text { artículo }\end{array}$ & $\begin{array}{l}\text { com } 1 \text { lâmina } \\
\text { mastigadora e } \\
2 \text { cerdas } \\
\text { plumosas }\end{array}$ & $\begin{array}{l}\text { com } 3 \text { lâminas } \\
\text { mastigadoras }\end{array}$ & $\begin{array}{l}\text { com } 3 \text { lâminas } \\
\text { mastigadoras }\end{array}$ \\
\hline 2. ${ }^{\circ}$ artículo & $\begin{array}{l}\text { com } 5 \text { cerdas } \\
\text { praticamente } \\
\text { iguais }\end{array}$ & $\begin{array}{l}\text { com } 5 \text { cerdas de } \\
\text { tamanhos } \\
\text { diferentes, } \\
\text { embora a } \\
\text { variação } \\
\text { entre elas } \\
\text { seja pequena }\end{array}$ & $\begin{array}{l}\text { com } 5 \text { cerdas } \\
\text { sendo } 4 \\
\text { pequenas, } \\
\text { relativamente } \\
\text { do mesmo } \\
\text { tamanho } \\
\text { e } 1 \text { muito longa } \\
\text { (cerca de } 7 \text { vezes } \\
\text { o tamanho da } \\
\text { menor) }\end{array}$ \\
\hline $\begin{array}{l}\text { Maxílula } \\
\text { protópodo }\end{array}$ & presente & presente & ausente \\
\hline lobo externo & $\begin{array}{l}\text { com } 3 \text { cerdas } \\
\text { pequenas }\end{array}$ & $\begin{array}{l}\text { com } 3 \text { cerdas } \\
\text { pequenas }\end{array}$ & $\begin{array}{l}\text { com } 2 \text { cerdas } \\
\text { pequenas e } \\
1 \text { grande }\end{array}$ \\
\hline $\begin{array}{l}\text { Vestígios de } \\
\text { maxílípedes } \\
\text { e patas }\end{array}$ & ausentes & presentes & ausentes \\
\hline $\begin{array}{l}\text { Relaçäo: } \\
\text { cerda maior } \\
\text { da armadura } \\
\text { caudal - } \\
\text { tamanho } \\
\text { do corpo }\end{array}$ & $\begin{array}{c}\text { aproximadamente } \\
1: 5,3\end{array}$ & $\begin{array}{c}\text { aproximadamente } \\
1: 6,5\end{array}$ & $\begin{array}{c}\text { aproximadamente } \\
1: 4,5\end{array}$ \\
\hline
\end{tabular}


Observando-se as 5 fases naupliares de $E$. rubescens podemos notar que a cerda do último artículo do exópodo da mandíbula é muito longa no náuplio I (cerca de 9 vezes o tamanho do artículo), atingindo quase a ponta da cerda furcal; à medida que o animal evolue, já no náuplio II, talvez devido ao aparecimento da maxílula, esta cerda vai diminuindo de tamanho relativo, sendo praticamente igual às demais no náuplio $\mathrm{V}$. Tal coisa não acontece com $E$. pharelatus.

Comparando $E$. rubescens e $E$. pharelatus nas diversas fases naupliares podemos notar que em todas, a primeira apresenta lâminas mastigadoras (na antena e mandíbula) mais delicadas que as da segunda. $O$ campo ciliar que aparece nas duas espécies na mesma fase, náuplio II, apresenta tamanho e posição diferente; sendo maior e inclinado em $E$. rubescens. A segmentação começa mais atrasada em $E$. rubescens, no náuplio III. O náuplio $\mathrm{V}$ desta espécie não apresenta quaisquer vestígios de patas ou outro qualquer assessório.

Os estudos de desenvolvimento para o gênero Ectocyclops contém descrições apenas das fases naupliares, de maneira que não pude comparar as fases de copepóditos.

Procurei estabelecer uma lei geral de crescimento de copepóditos para a espécie Ectocyclops rubescens.

$\mathrm{O}$ crescimento de copépodos se dá, na realidade entre as mudas, dentro da cutícula de quitina. No entanto, a variação só pode ser notada após a muda, assim como as novas peças e as transformações só entrarão em atividade após a mesma. A cada muda corresponde um fase. Neste particular estes animais se distinguem dos crustáceos superiores os quais podem apresentar várias mudas para uma mesma fase.

Vários autores admitem que o crescimento de crustaceos obedeça a seguinte lei:

$$
\mathbf{B}=\beta \mathrm{e}^{\alpha \mathrm{S}}
$$

onde $\mathrm{B}$ é o comprimento do corpo, $\mathrm{S}$ o número da fase e $\beta$ e $\alpha$ são constantes. Esta lei é conhecida por lei de Brooks.

Teissier (1960) nega que essa lei de crescimento possa ser generalizada para todos os crustáceos mas admite que ela seja válida para muitos deles.

Hanaoka (1952) estudando náuplios de copépodos de várias espécies pertencentes às 3 sub-ordens - Calanoida, Cyclopoida e Harpacticoida - conclui que esses animais quando bentônicos, cos- 
teiros (marinhos) ou de água doce obedecem a lei de Brooks. Os planctônicos marinhos têm uma forma de crescimento diferente. Tentamos por meio deste estudo verificar qual a forma de crescimento de Ectocyclops rubescens e assim confirmar ou não as conclusões de Hanaoka.

Obtive para Ectocyclops rubescens uma taxa de crescimento de $14 \%$. O animal cresce segundo a lei de Brooks. Isto corrobora os trabalhos de Hanaoka (1952) com Cyclops serrulatus, Mesocyclops leuckarti e Cyclops strenuus.

\section{7.}

\section{CONCLUSŌES}

Ectocyclops rubescens, Brady 1904 é um Cyclopoida de água doce muito comum no Estado de São Paulo. Embora bom nadador, vive mais junto à vegetação, quer da margem, quer flutuante, desde que a mesma seja envolvida por detritos. Seu ciclo de vida é relativamente curto, levando de náuplio I a adulto, 25 dias em média. Seu desenvolvimento compreende dez fases: cinco fases de náuplios e cinco de copepóditos.

As fases naupliares compreendem: um ortonáuplio e quatro metanáuplios. O ortonáuplio é arredondado e os metanáuplios ovais. As principais características dos náuplios são:

1 - Antênula - sempre com quatro artículos, aumentando as cerdas e os espínulos gradativamente até a fase de náuplio $\mathrm{V}$ quando possue 6 cerdas no artículo terminal, 2 no terceiro e 1 no segundo.

2 - Antena - com o mesmo número de artículos nas cinco fases, aumentando, gradativamente, o número de cerdas, espinhos e espínulos até o náuplio $\mathrm{V}$ quando tem 15 cerdas e 1 espinho mastigador.

3 - Mandíbula - também com o mesmo número de artículos nas cinco fases. Nota-se nesta peça uma diminuição do tamanho relativo das cerdas, principalmente a do artículo distal, do exópodo.

4 - Maxílula - aparece no primeiro metanáuplio representada por um par de cerdas espinhosas. No náuplio $V$ esta peça apresenta um basípodo e dois lobos com cerdas, uma das quais tão longa que atinge a ponta da cerda furcal. 
5 - Campo ciliar - aparece na fase II.

6 - Segmentação - só aparece na fase III.

7 - Armadura caudal - com um par de cerdas na fase I e três pares no náuplio $\mathrm{V}$.

8 - Vestígios de maxilípides e patas - ausentes.

As cinco fases de copepóditos apresentam as seguintes características principais:

1 - Corpo - o animal apresenta desde o copepódito I o aspecto "atarracado" do adulto.

2 - Antênula - esta peça só toma forma definitiva no adulto. No copepódito I apresenta quatro artículos, e, no V, sete, portanto, não aumenta muito o número de artículos.

3 - Furca - tem inicialmente apenas uma cerda grande mas no estágio III, já atinge o aspecto que terá no adulto. A relação "tamanho do corpo-tamanho da furca" já se estabelece neste ponto.

4 - Patas - aumentam em número e complexidade a partir de copepódito I, aparecendo já completamente formadas no copepódito $\mathrm{V}$.

5 - Abertura genital - sempre ausente.

Ectocyclops rubescens cresce segundo a lei de Brooks e apresenta uma taxa de crescimento de $14 \%$.

Devido a todas as diferenças já discutidas, podemos afirmar que $E$. rubescens é realmente uma espécie distinta de $E$. pharelatus.

8.

\section{SUMÂRIO}

Ectocyclops rubescens de facil criação em laboratório foi coletado em São Paulo (Campus da Cidade Universitária), Guarulhos e Americana (no Estado de São Paulo).

Um estudo detalhado das fases de desenvolvimento de Ectocyclops rubescens foi realizado. As fases naupliares apresentam as carecterísticas do Quadro VII. As fases de copepóditos apresentam as características do Quadro VIII.

A espécie cresce segundo a lei de Brooks e apresenta uma taxa de crescimento de $14 \%$. 


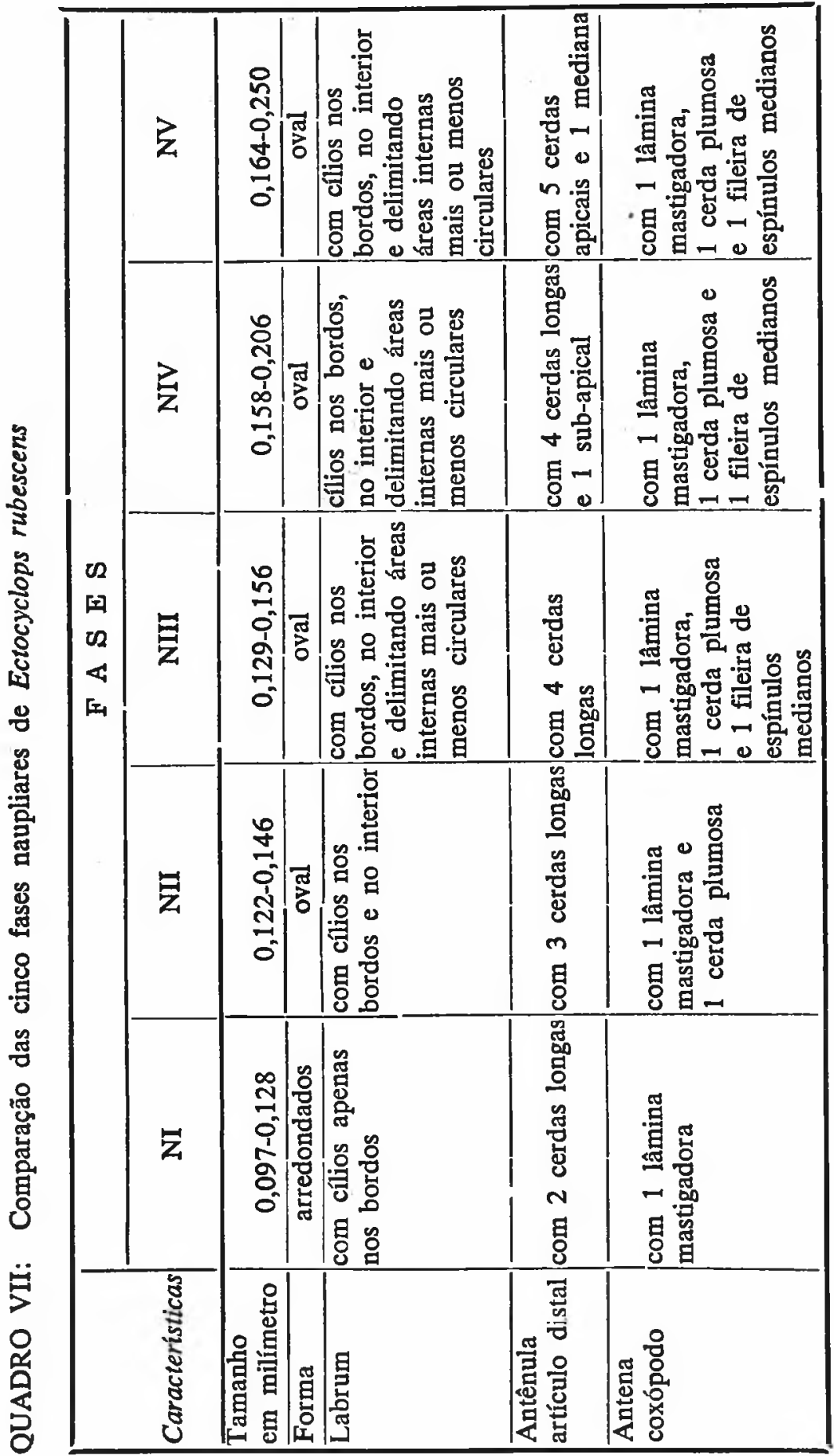




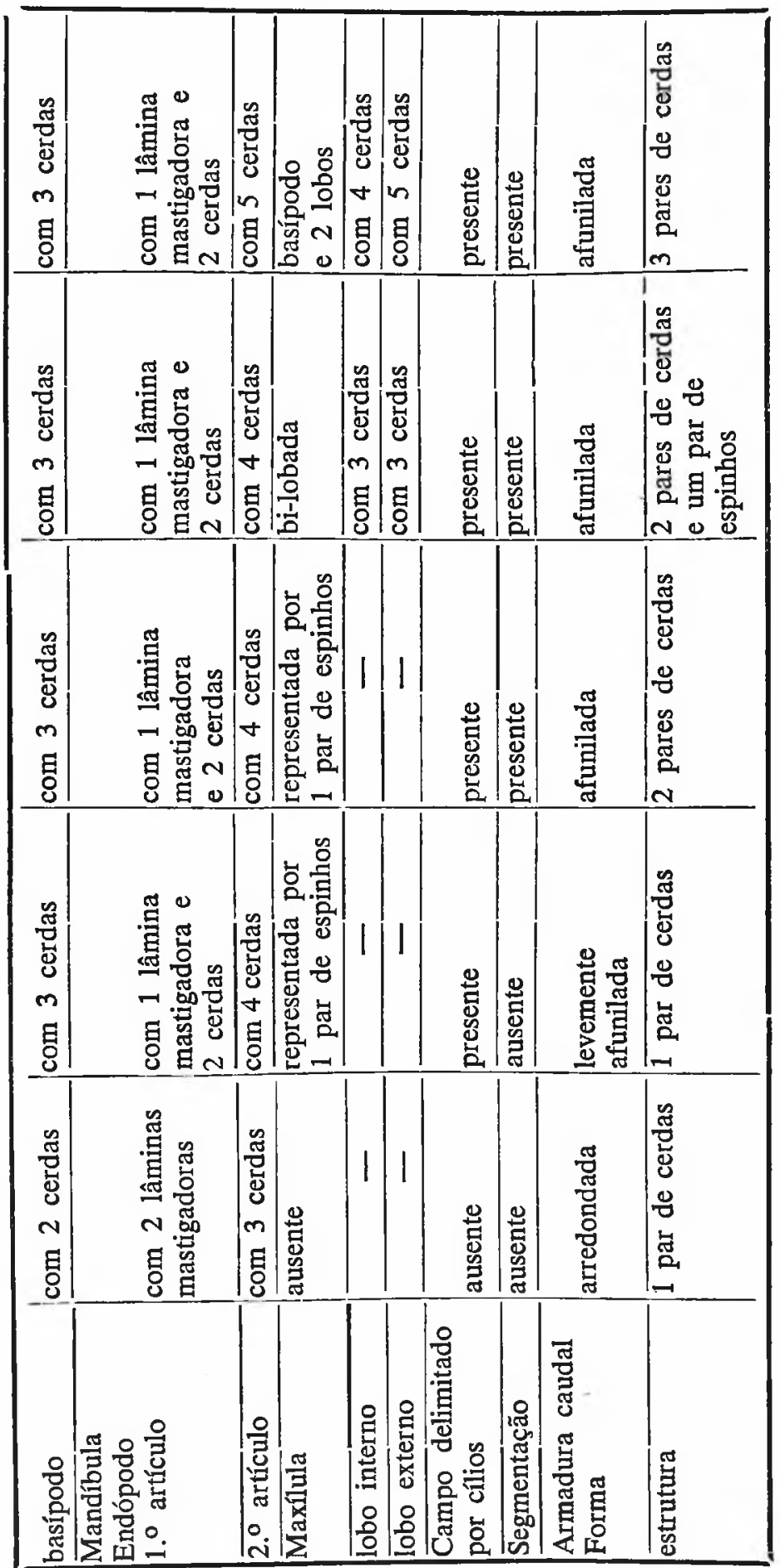




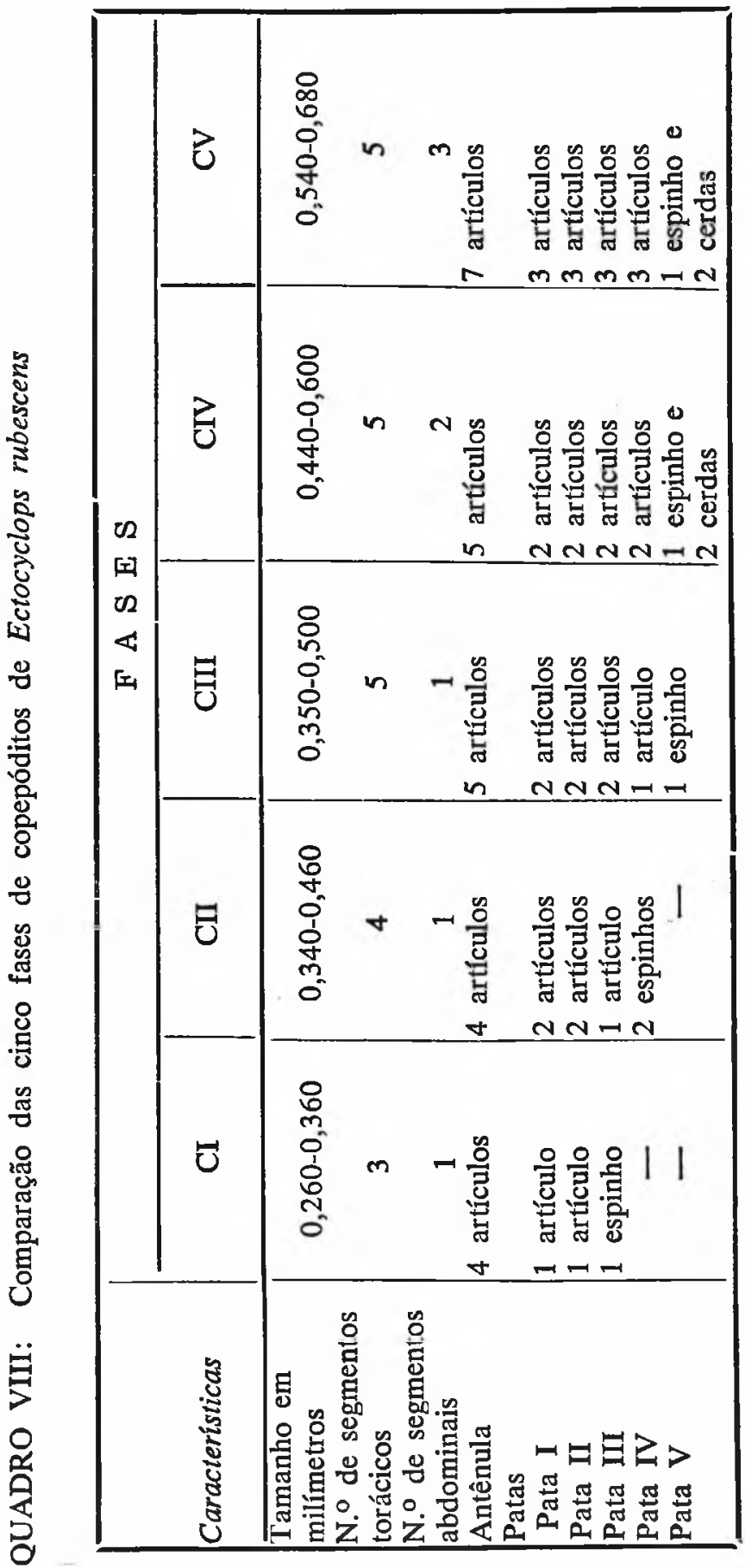


9.

\section{SUMMARY}

This is the first report of the species Ectocyclops rubescens for Brazil. It was already know for South America, Paraguay (Linlberg 1954).

Dussart (1969) considers E. rubescens a subspecies of $E$. pharelatus Kiefer (in Rilov, 1963) considers it a distinct species.

The study of the material here described shows that $E$. rubescens differs from $E$. pharelatus in the adult stage by the characteristics listed below:
E. rubescens
E. pharelatus

Article 6 of antennule short.

Most internal seta of leg 5 with two different spines: small and thick at the end, and, long and thin from the base to the end. Most external seta of leg 5 with slender spines.

Male antennule 11-articulated, with article 5 and 8 partially divided into 2 articles and 3 articles respectively.

All mouth appendages complex.
Article 6 of antennule long. All the spines of leg 5 similar.

Most external seta of leg 5 without spines.

Male antennule with 17 articles.

Mouth appendages simple.

$E$. rubescens was reared in the laboratory and developed from nauplius $I$ to adult in 25 days (average).

Five naupliar stages were observed during laboratory rearing experiments: one orthonauplius and four metanauplii. The orthonauplius is roundish and the metanauplii are oval. The most important characteristics of the 5 naupliar stages are compared in the folllowing table: 


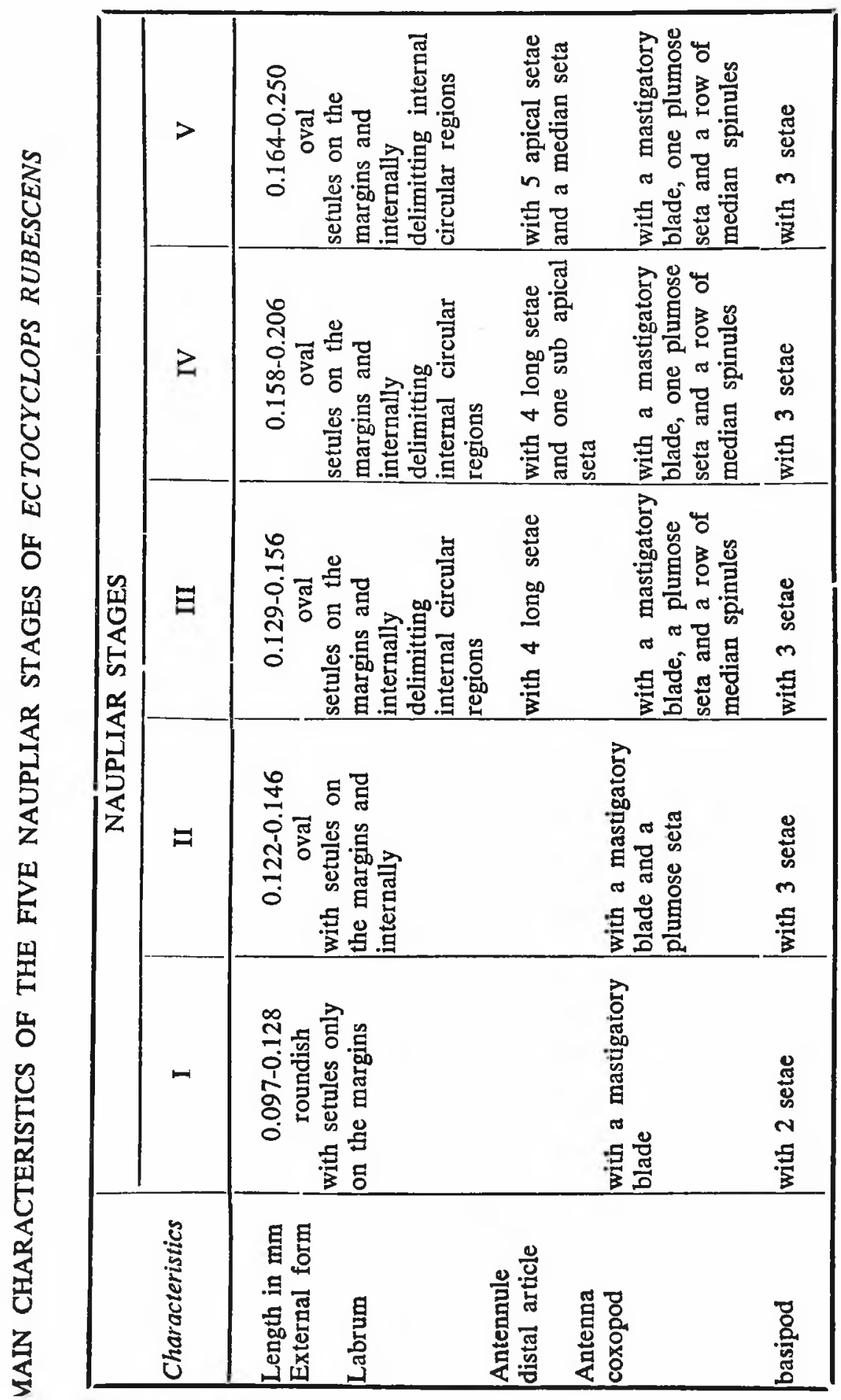




\begin{tabular}{|c|c|c|c|c|}
\hline$>$ & 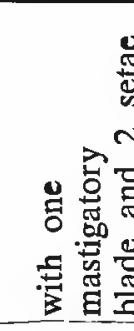 & 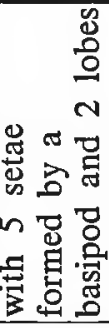 & 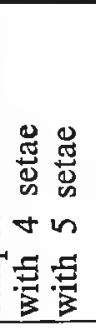 & 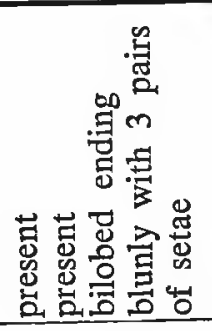 \\
\hline$\varepsilon$ & 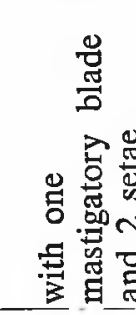 & 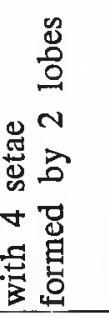 & 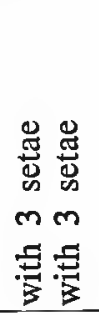 & 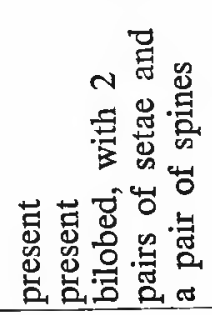 \\
\hline 兒 & 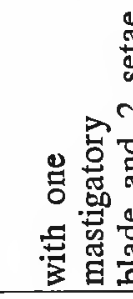 & 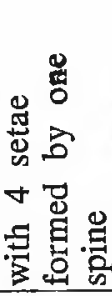 & 11 & 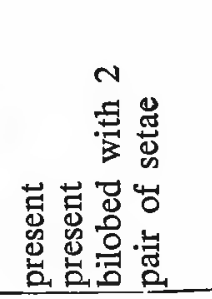 \\
\hline$\models$ & 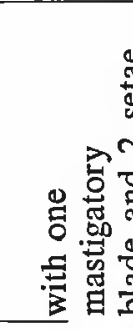 & 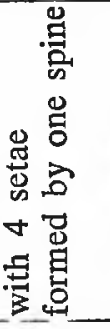 & 11 & 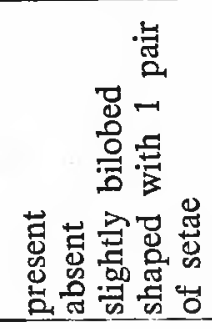 \\
\hline$\mapsto$ & 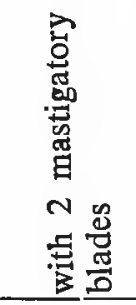 & 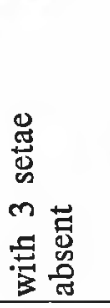 & 11 & 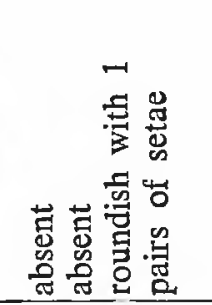 \\
\hline 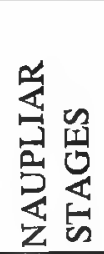 & 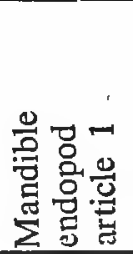 & 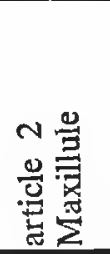 & 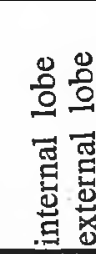 & 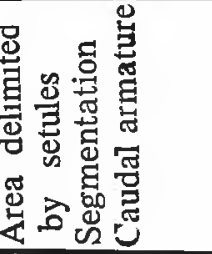 \\
\hline
\end{tabular}


On comparing the naupliar stages of $E$. rubescens and $E$. pharelatus (see Ewers, 1930, and Dukina in Dussart, 1969) a difference between the developmental characterisctics of the two species is noted, thus proving thant they are different.

$E$. rubescens grows according to the Brooks $(B=\beta$ e $\alpha S)$ at a rate of $14 \%$.

Samples of $E$. rubescens were collected in São Paulo (University Campus), in Guarulhos (S. Paulo), and in Americana all in the State of São Paulo (South of Brazil); also in the Tocantins River area, in the North of Brazil (State of Pará).

\section{BIBLIOGRAFIA}

AUVRAY, C. \& DUSSART, B. - 1966 - Role de quelques facteurs du milieu sur le développement post-embryonnaire des Cyclopides (Crustacés Copépodes). I. - Géneralités. Cas de Eucyclops. Bull. Soc. Zool. France, 91 (3): 447-491.

AUVRAY, C. et DUSSART, B. - 1967 - Role de quelques facteurs du milieu sur le développement post-embryonnaire des Cyclopides (Crustacés Copépodes). Bull. Soc. Zool. France, 92, (1): 11-22.

BRADY, G. St. - 1904 - On Entomostraca collected in Natal by Mr. James Gibson. Proc. Zool. Soc. London 2: 121-128.

DIETRICH, W. - 1915 - Die Metamorphose der freilebenden Süsswasser Copepoden. I. Die Nauplien und das erste Copepodidstadium. Z. wiss. Zool., 113: 252-324.

DUSSART, B. - 1967 - Les Copépodes des eaux continentales, 1: 500 p. Boubée, Paris.

DUSSART. B. - 1969 - Les Copépodes des eaux continentales, tome II - Cyclopoides et Biologie - 292 p. Boubée, Paris.

Ewers, L.A. - 1930 - The larval development of freshwater Copepoda. Contr. Frans Theodore Stone Inst. Hidrobiol., 3: 1-43, 13 t.

Hanaoka, T. - 1952 - Study on free-living Copepoda-nauplius. Bull. Naikai Reg. Fish. Res. Lab. 1 (contrib. 1): 1-36.

Kiefer, F. - 1929 - Cyclopoida Gnathostoma. Das Tierreich. 102 p. Walter de Gruyter. Berlin.

KIEFER, F. - 1933 - Süusswassercopepoden aus Brasilien. Zool. Anz. 105: 38-43.

KIEFER, F. - 1935 - Ueber drei Cyclopiden (Crust. Copepoda) aus Brasilien. Zool. Anz. 112: 23-31.

KIEFER, F. - 1936 a - Brasilianische Ruderfusskrebse Crust. Copepoda), gesammelt von Herrn Dr. O. Schubart. II Mit. Zool. Anz. 114: $129-133$.

KIEFER, F. - 1936 b - Brasilianische Ruderfusskrebse (Crust. Copepoda), gesammelt von Herrn Dr. O. Schubart. III. Mit. Zool. Anz. 114: $320-322$. 
KIEFER, F. - 1936 c - Brasilianische Ruderfusskrebse (Crust. Copepoda), gesammelt von Herrn Dr. O. Schubart. V. Mit. Zool. Anz. 116: $31-35$.

KIEFER, F. - 1952 - Exploration du Parc National Albert. Inst. des Parcs Nationaux du Congo Belge. 21: 1-136.

LESCHER-MOUTOUE, F. - 1966 - Note sur la reproduction et le développment post-embryonnaire des Speocyclops. Ann. Spéléc. 21, (3): $673-688$

LINDBERG, K. - 1954 - Cyclopides (Crustacés Copépodes) de l"Amerique du Sud. Ark. Zool., 7 (3): 193-222.

OLIVEIRA, L.P.H. de, - 1954 - Sobre a presença do copépoda Mesocyclops longisetus (Th.) no pláncton de uma litorânea, Mem. Inst. Osw. Cruz 52: 239-244

RILOV, V.M. - 1963 - Fauna of USSR Freshwater Cyclopoida 314 p. translated from Russian by Israel. 3 (3): Program for Scientific Translations - Jerusalem.

SARS, G. O. - 1918 - An Account of the Crustacea of Norway (with short descriptions and figures of all the species) Copepoda Cyclopoida. 6: 225 p. 118 t. Bergen Museum - Bergen.

TEISSIER, G. - 1960 - Relative growth. In: Waterman T. (ed.) The physiology of Crustacea, 1: 537-560 Academic Press, New York. ZIEGELMAYER, W. - 1925 - Metamorphose und Wachstum der Cylopidae. Z. wiss, Zoll., 126: 493-570. 


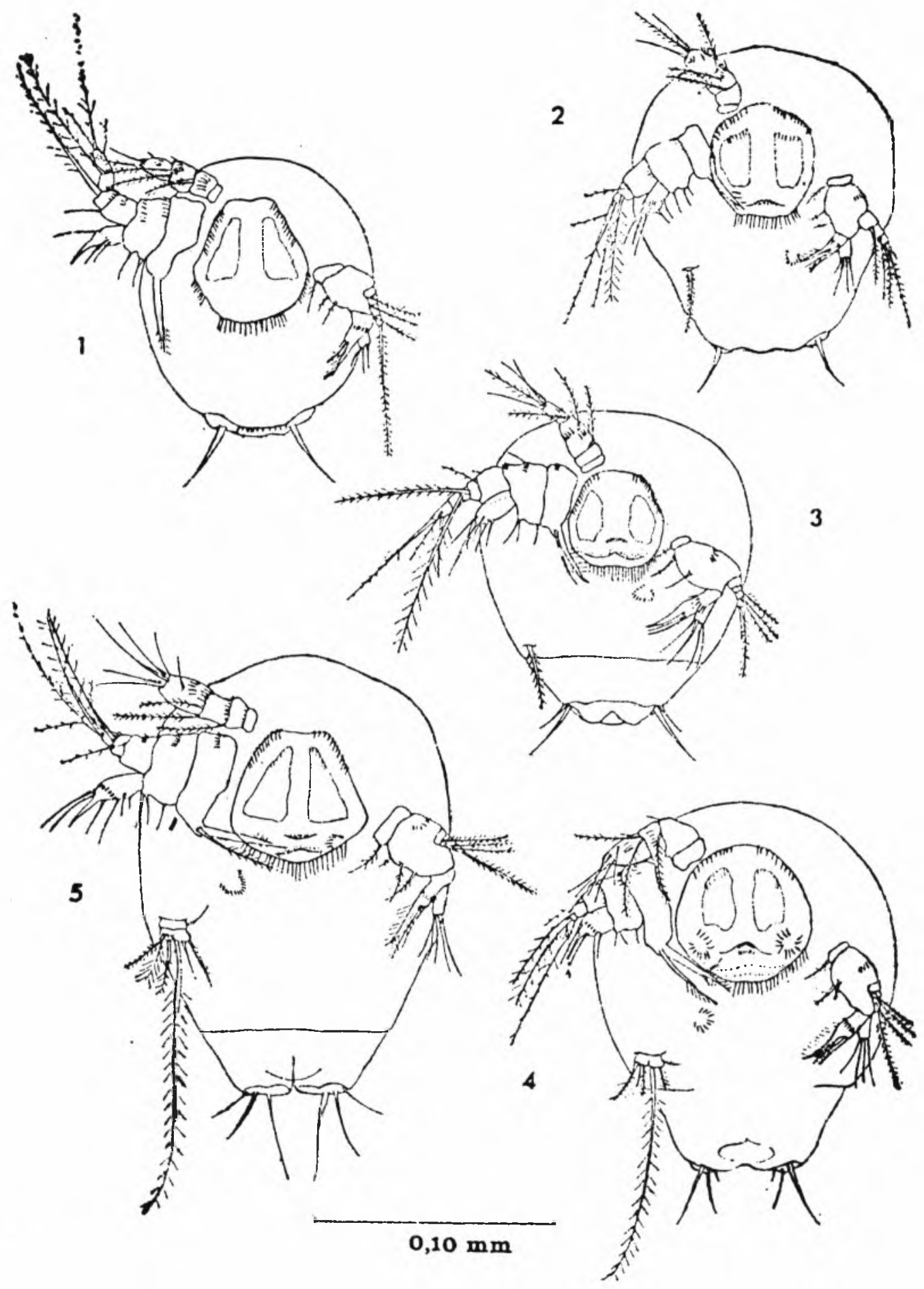



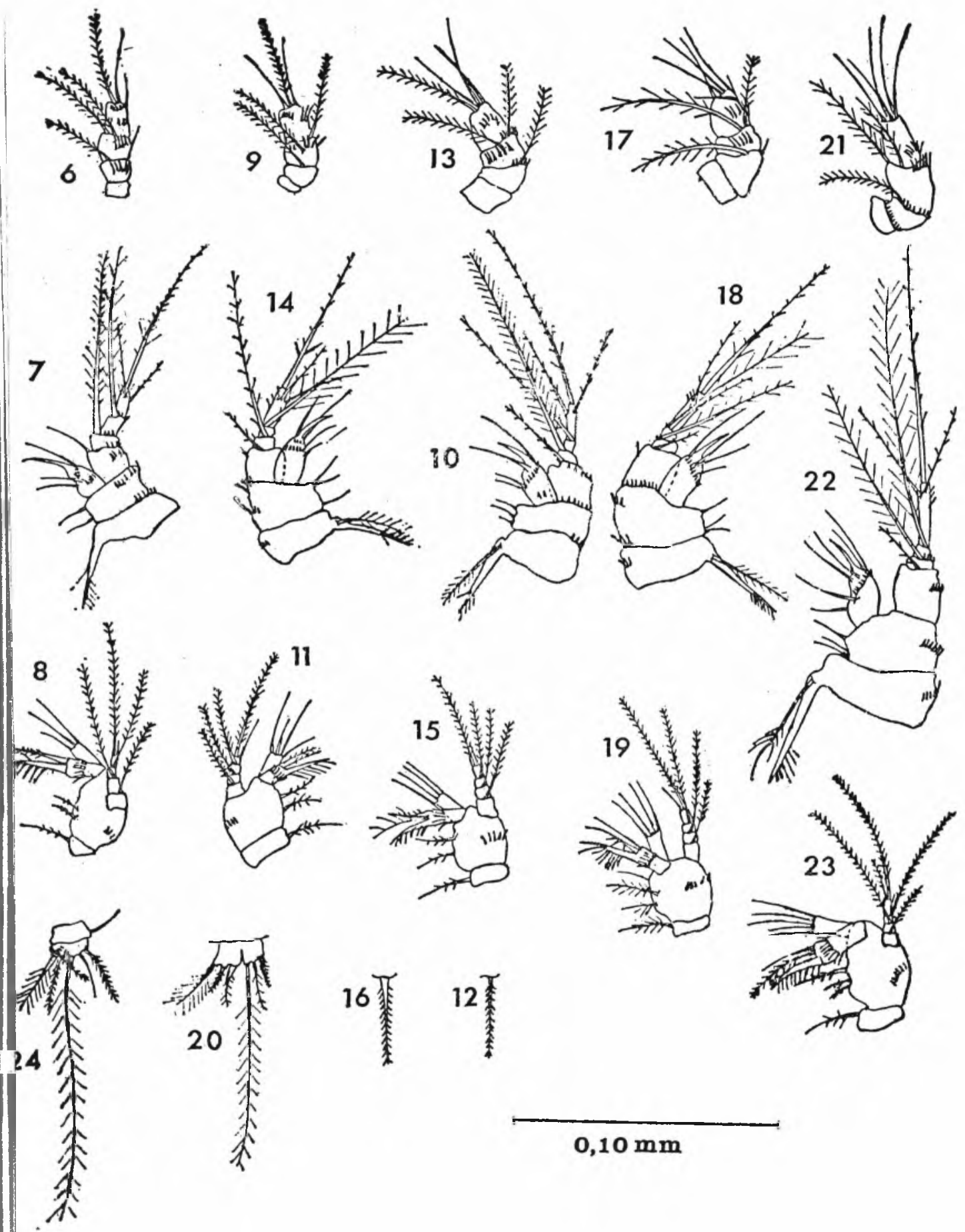


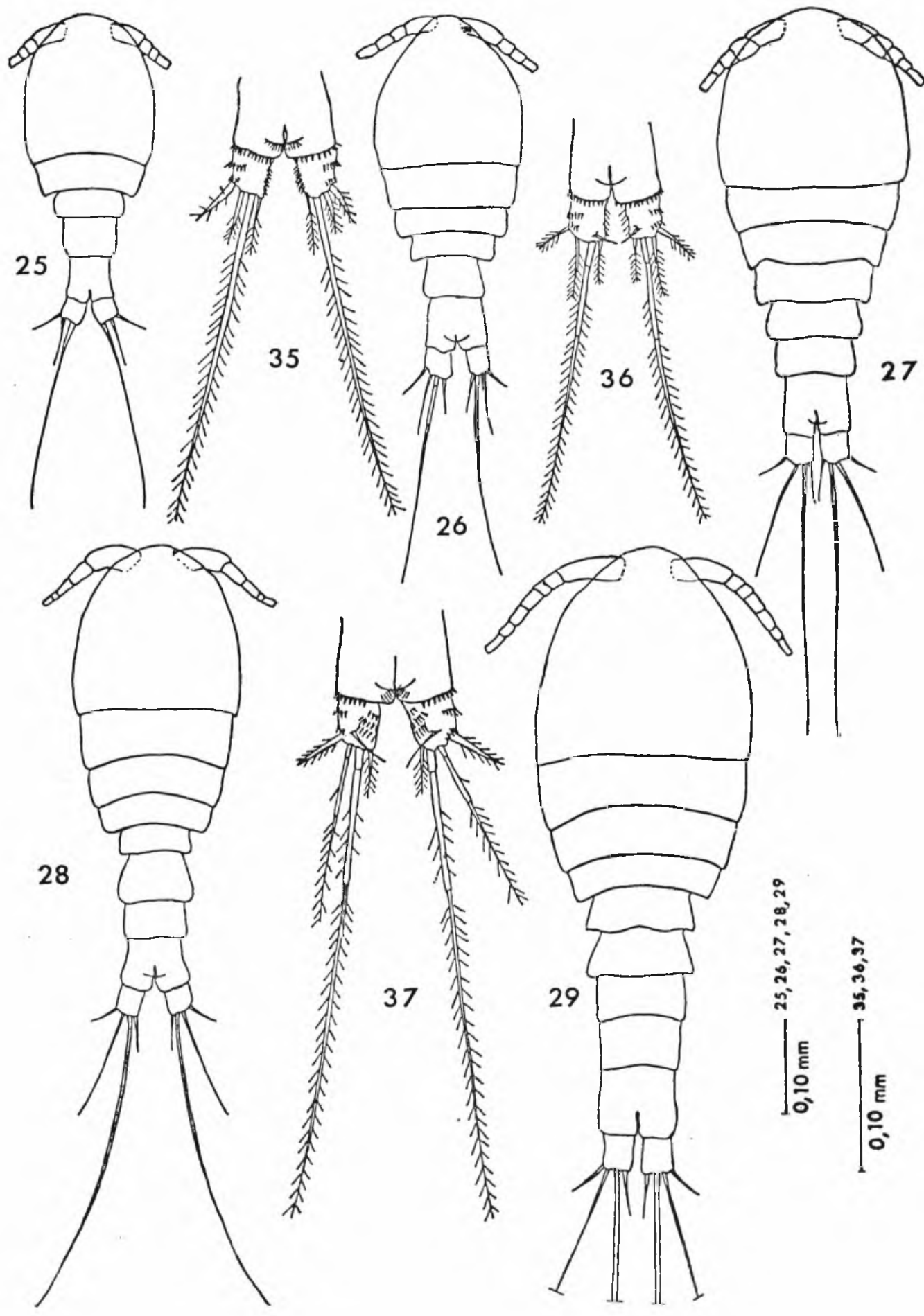




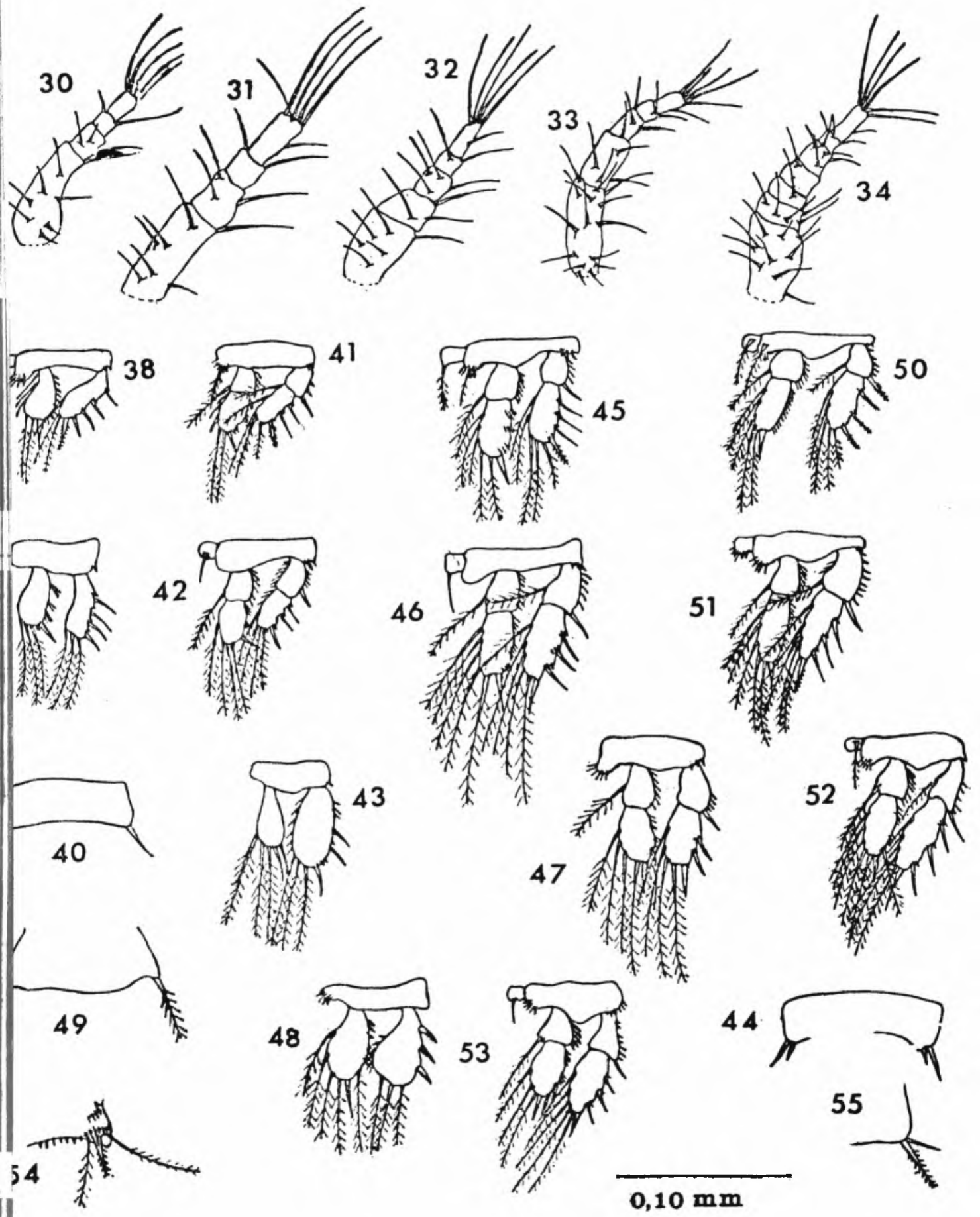



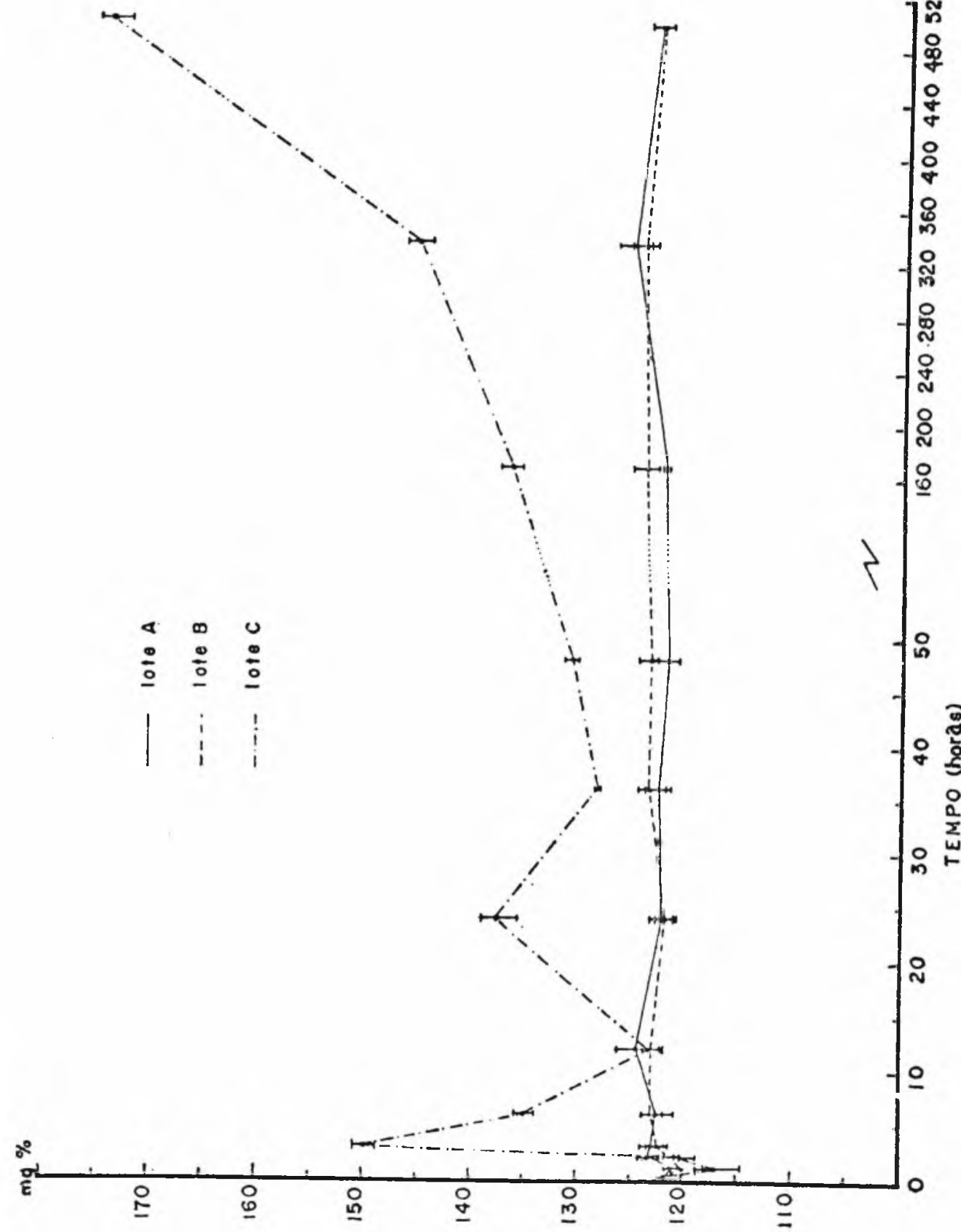

ט」-UwI-

Fig. 20 - Glicemia em Rhamdia sebae - Gráfico da tabela 5 - Variação da glicemia em animais testemunhos (lote A) operados-testemunhos (lote B) e urofisectomizados (lote C). 


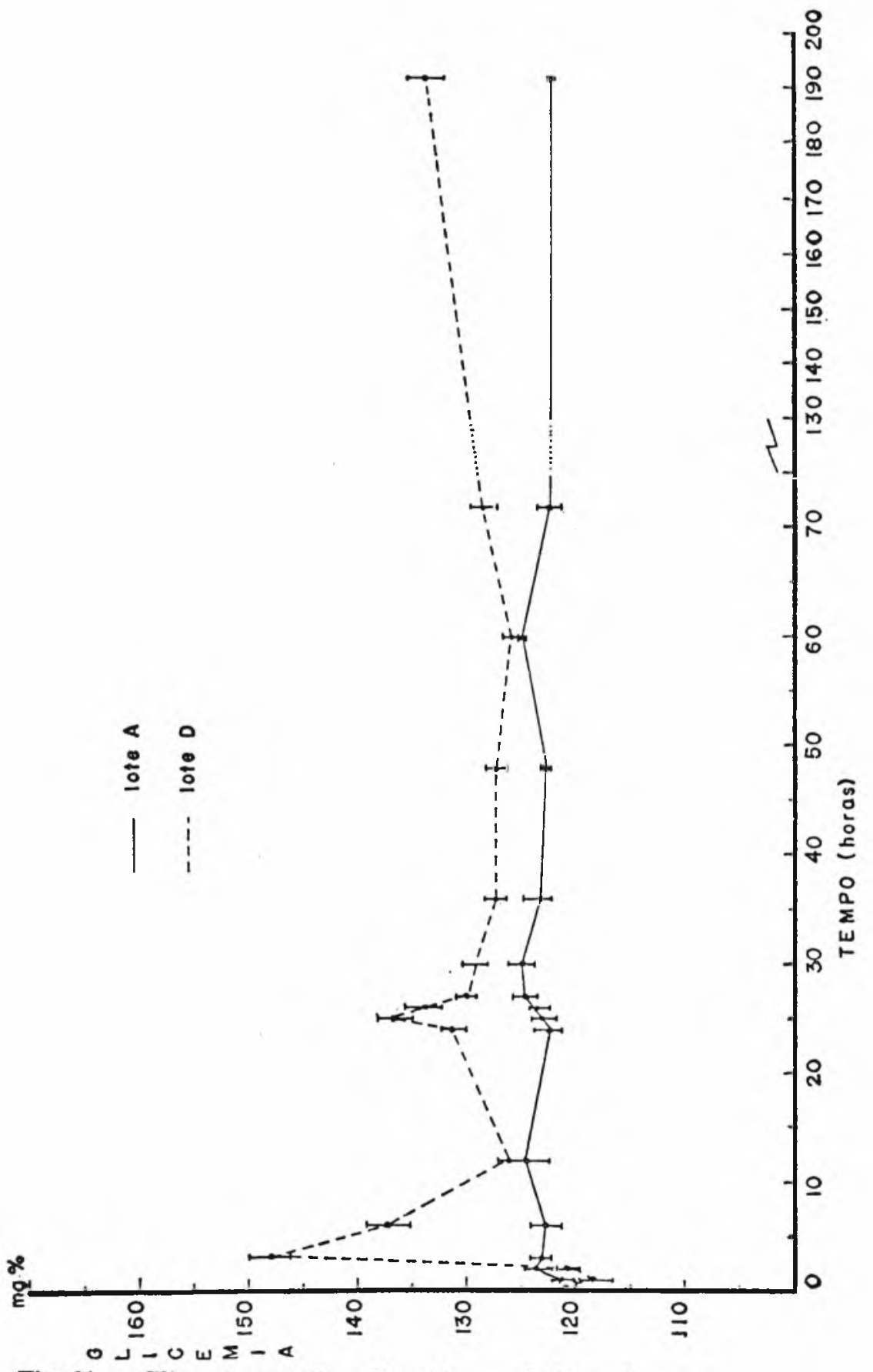

Fig. 21 - Gìcemia em Rhamảia sebae - Grảfico da tabela 6 - Varíação da glicemia em animais urofisectomizados (lote $D$ ) sob a ação de extrato de urófise a partir de 24 horas. 


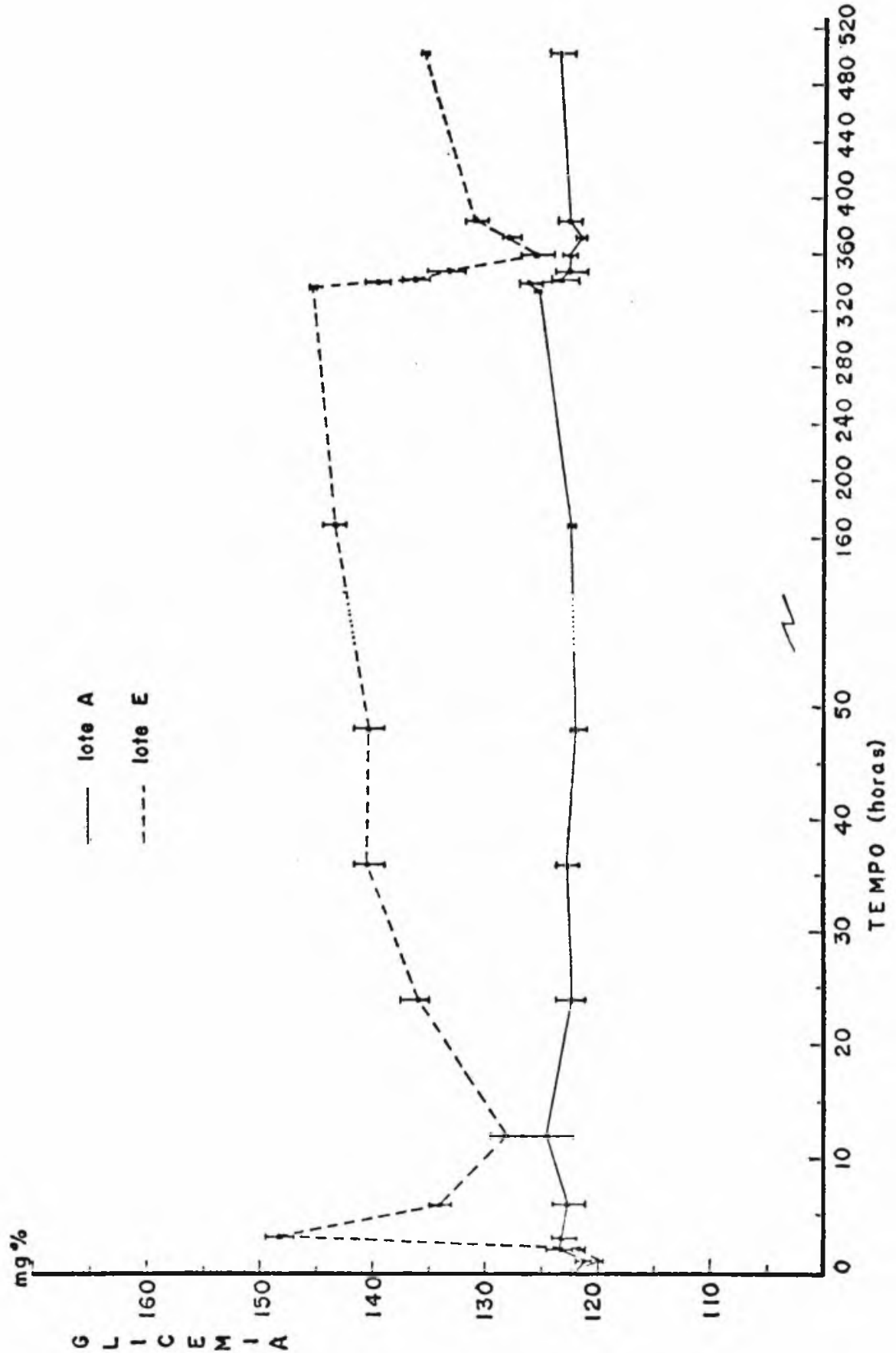

Fig. 22 - Glicemia em Rhamdia sebae - Gráfico da tabela 7 - Variação da glicemia em animais urofisectomizados (lote $\mathrm{E}$ ) sob ação de extrato de urófise a partir de 336 horas (2 semanas). 


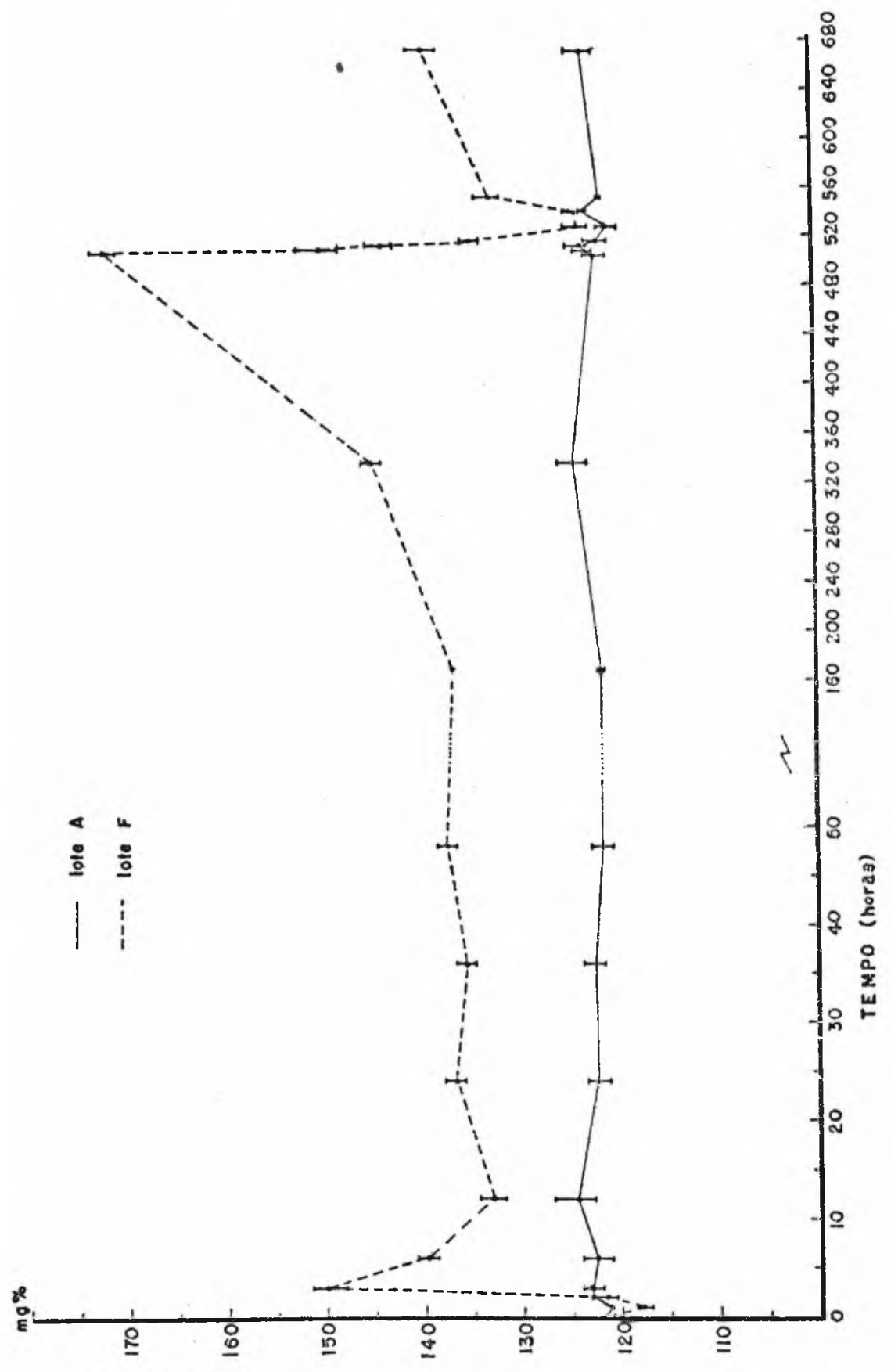

o $\lrcorner-u \omega \Sigma-<$

Fig. 23 - Glicemia em Rhamdia sebae - Gráfico da tabela 8 - Variação da glicemia em animais urofisectomizados (lote F) a partir de 504 horas ( 3 semanas), sob a ação do extrato de urófise. 
